University of Redlands

\title{
Georepresentation of Populations at Seven Spanish Missions in Alta California
}

A Major Individual Project submitted in partial satisfaction of the requirements

for the degree of Master of Science in Geographic Information Systems

by

Katherine M. Smyth

Fang Ren, Ph.D., Committee Chair

Russell Weaver, Ph.D.

December 2013 
Georepresentation of Populations at Seven Spanish Missions in Alta California

Copyright (C) 2013

by

Katherine M. Smyth 
The report of Katherine M. Smyth is approved.
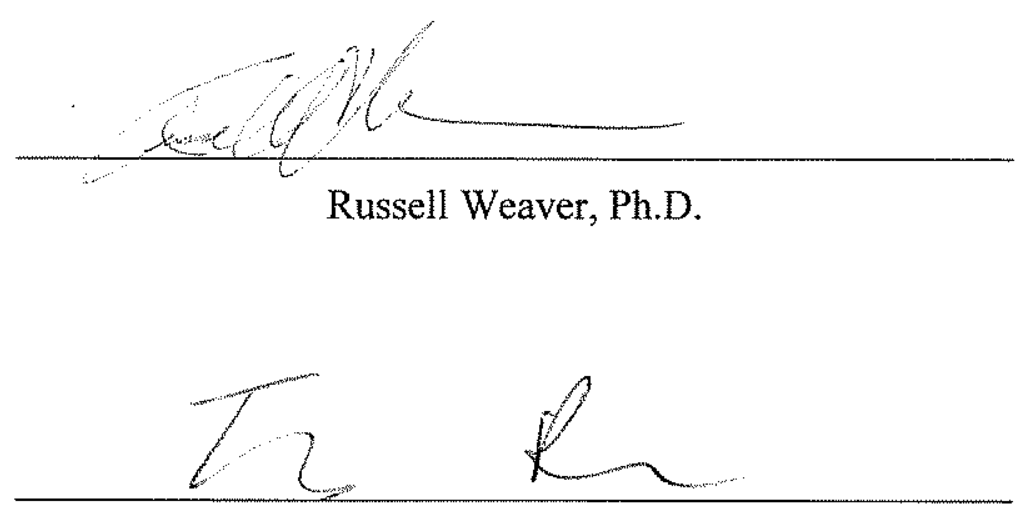

Fang Ren, Ph.D., Committee Chair

December 2013 



\section{Acknowledgements}

This project could not have been completed without the guidance, help, input and support of many people.

First, I would like to thank James and Tish Sandos for allowing me to play a small part in their research with the implementation of this project and for their infectious enthusiasm for a very important subject. In the same breath, I would also like to recognize the many hours that Dr. Fang Ren has patiently spent helping me craft this project. Many thanks as well to Dr. Russell Weaver for his interest in this project and creative statistical insight. I would also like to thank Dr.'s Kumler, Flewelling and Ma for their insight whenever I needed guidance along a new path, and sometimes even when I didn't think I needed it. Big thanks to Debbie Riley for her wisdom and kindness.

It goes without saying that I am indebted to my colleagues in Cohorts 22, 23 and 24 for their personal support and their inspiring, energetic thirst for knowledge. Special thanks to Pon Lertsakdadet of Cohort 20 for sharing his JavaScript expertise at a crucial time. Additional thanks goes to Steve Norris of Cohort 8 for passing on his knowledge of GIS and for his insight throughout the majority of this program.

I would like to thank my friends, old and new, for their support and understanding. Thanks in particular to Tom White for his compassionate encouragement throughout the year.

Finally, I would like to thank my family. From an early age my parents taught me to follow my interests and have supported me on the myriad of paths that have led to the

place I am now. I am grateful for the value that they place on adventure and the pursuit of knowledge, and for their unwavering encouragement in endeavors such as this. 



\begin{abstract}
Georepresentation of Populations at Seven Spanish Missions in Alta California by

Katherine M. Smyth

Geospatial information is integral in helping historians and students understand the past. This project incorporated data culled from historical records concerning baptized individuals at seven missions kept by Spanish priests into a GIS environment. Individuals with a known origin, birth date, baptismal date and death date were given locational coordinates based on corresponding regional data. This spatial relationship allowed for statistical analysis of longevity of individuals within mission outreach populations. A web application with four primary functionalities was developed to provide visual context for historians and students regarding the California mission system in the San Francisco Bay Area. Functionalities of the web application include a query of baptized individuals, dynamic representation of descriptive statistics, interactive temporal representation of individuals with a time slider, and comparative display of mission outreaches. The products of this project are intended to provide a basis for further georepresentation of historical populations within GIS and on the web.
\end{abstract}





\section{Table of Contents}

Chapter 1 - Introduction ......................................................................................................... 1

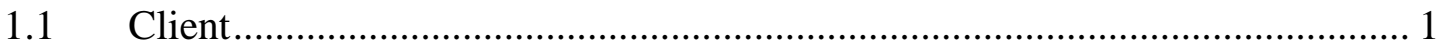

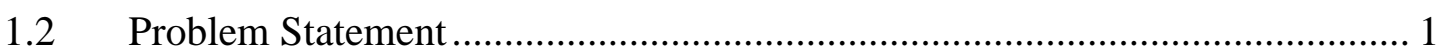

1.3 Proposed Solution ................................................................................... 2

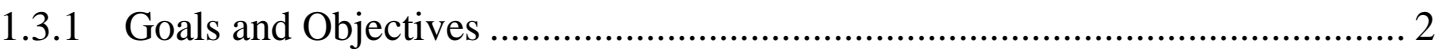

1.3.2 Scope

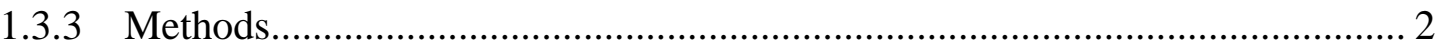

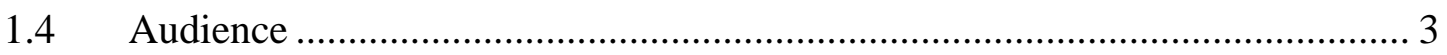

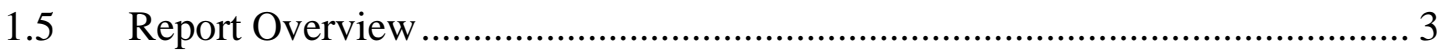

Chapter 2 - Background and Literature Review ................................................................ 7

2.1 Brief Overview of the Spanish Mission System ............................................. 7

2.2 Georepresentation of Indigenous Individuals with GIS ................................. 9

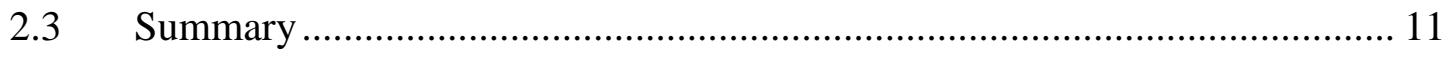

Chapter 3 - Systems Analysis and Design...................................................................... 15

3.1 Problem Statement ........................................................................... 15

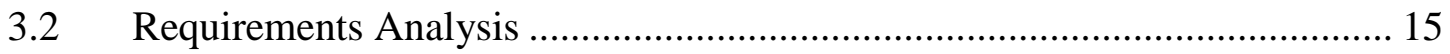

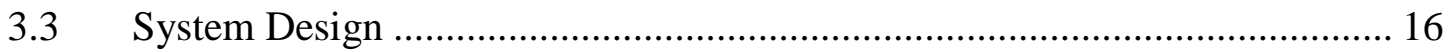

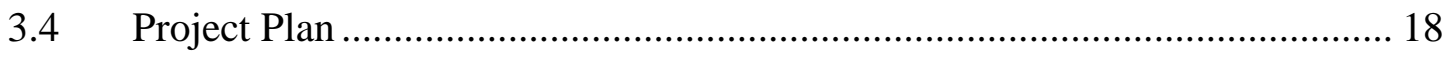

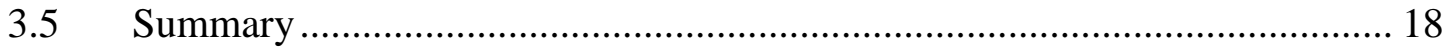

Chapter 4 - Database Design...................................................................................................... 21

4.1 Conceptual Data Model ....................................................................... 21 


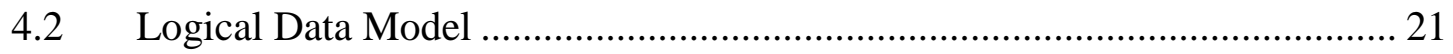

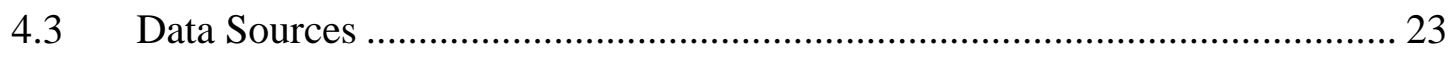

4.4 Data Scrubbing and Loading ………………………............................. 23

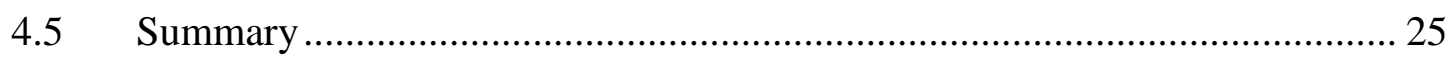

Chapter 5 - Web Application Implementation.................................................................. 27

5.1 ArcGIS Desktop Application ................................................................... 27

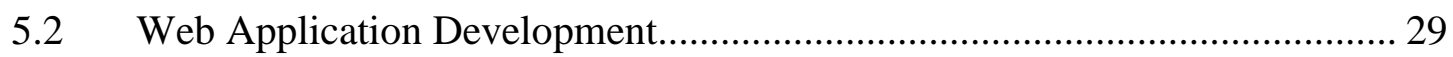

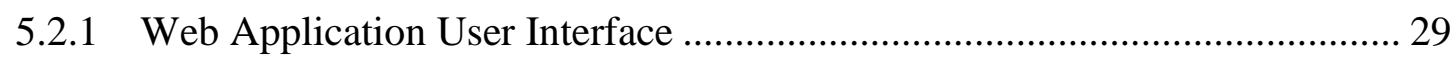

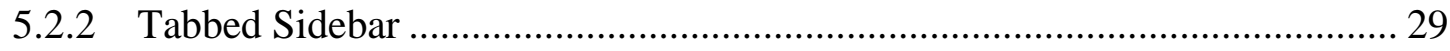

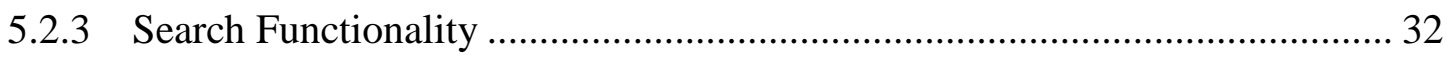

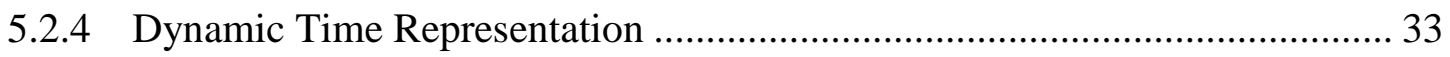

5.2.5 Popup Functionality with Descriptive Statistics ............................................. 34

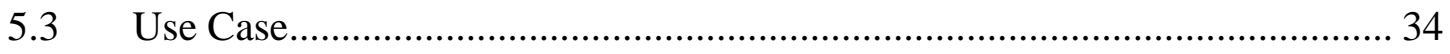

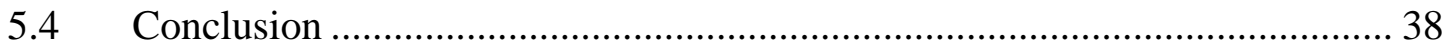

Chapter 6 - Results and Analysis...................................................................................... 39

6.1 Statistical Analysis Methods........................................................................ 39

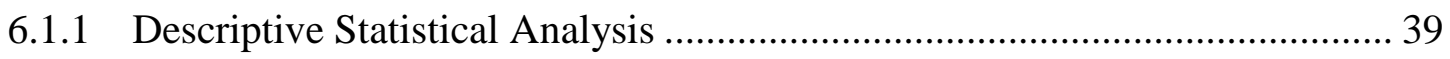

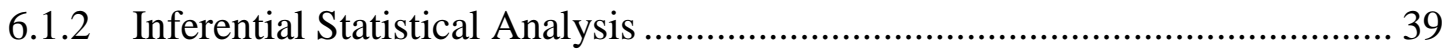

6.2 Mission Population Overview................................................................... 41

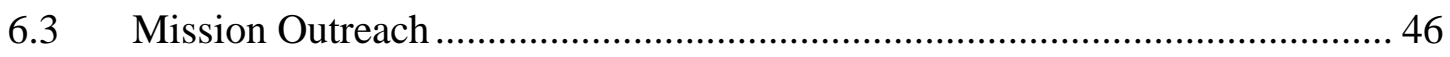

6.4 Longevity of Baptized Individuals.................................................................. 48

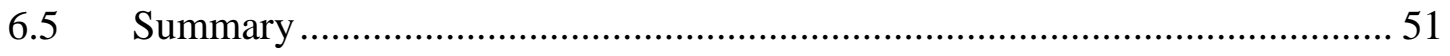

Chapter 7 - Conclusions and Future Work ..................................................................... 53 
Works Cited 55

Appendix A. Client Statement (Web Application) ........................................................ 57

Appendix B. Web Application Code …......................................................................... 58 



\section{Table of Figures}

Figure 2.1 Indigenous Language Groups ............................................................. 8

Figure 2.2 Outreach Areas by Mission ................................................................. 10

Figure 4.1 Conceptual Data Model .......................................................................21

Figure 4.2 Logical Data Model .............................................................................22

Figure 5.1 MissionGIS File Database ……………………....................................2

Figure 5.2 ArcGIS Data Analysis Capability (Population Density) ..........................28

Figure 5.3 User Interface Layout .........................................................................29

Figure 5.4 Tabbed Sidebar User Interface .............................................................

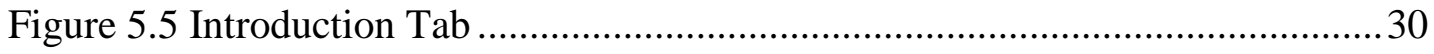

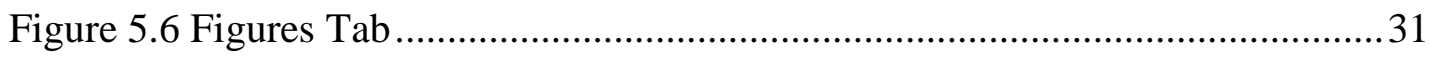

Figure 5.7 Mission Outreach Checkbox Example and Result on Map........................32

Figure 5.8 Search Box, Graphic Results on Map and Grid ........................................33

Figure 5.9 Time Slider with Defined Range and Results .........................................33

Figure 5.10 Mission Popup Info Window................................................................... 34

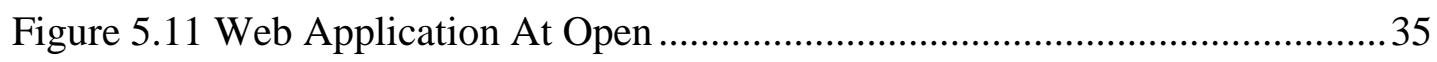

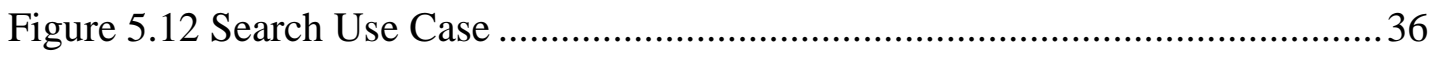

Figure 5.13 Shifting Influences of Missions Over Time ……....................................37

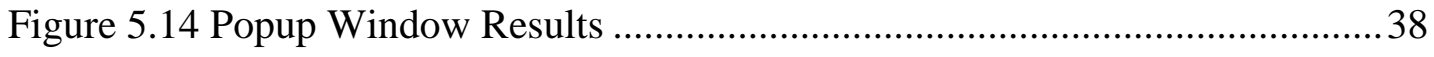

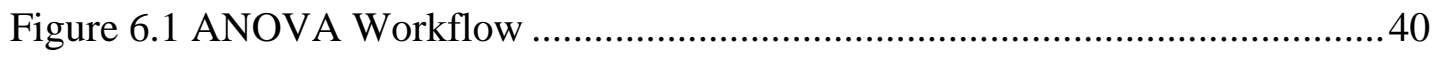

Figure 6.2 Independent Samples $t$ Test Workflow .................................................4

Figure 6.3 Missions Santa Clara de Asis and San Jose Outreach Overlap .................47 


\section{List of Tables}

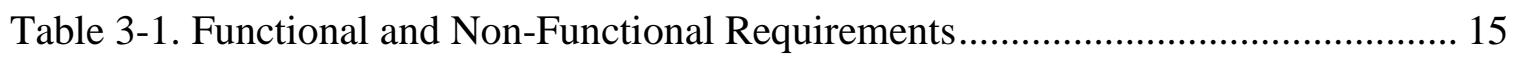

Table 4-1. Mission Codes and Numerical Classifications ........................................... 24

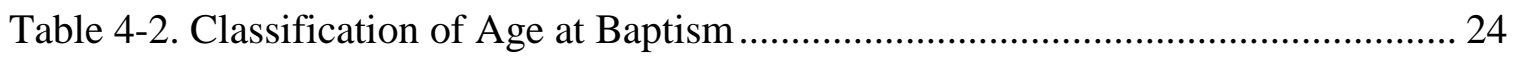

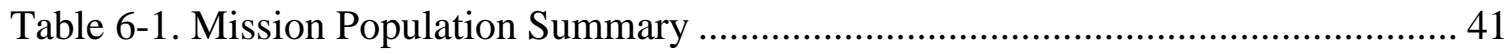

Table 6-2. Percentage of Ages at Baptism of Mission and Tribal Origin Individuals...... 43

Table 6-3. Longevity of Individuals After Baptism by Gender and Origin 1787-1840 ... 46

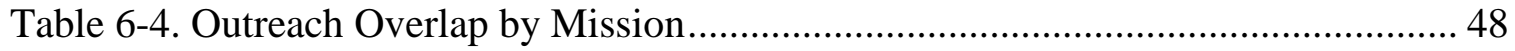

Table 6-5. Average Years Lived After Baptism by Origin.......................................... 49

Table 6-6. Longevity of Individuals After Baptism by Age Baptized 1787-1840 .......... 50 



\section{List of Acronyms and Definitions}

$\begin{array}{ll}\text { ANOVA } & \text { Analysis of Variance } \\ \text { API } & \text { Application Programming Interface } \\ \text { CSS } & \text { Cascading Style Sheets } \\ \text { GIS } & \text { Geographic Information Systems } \\ \text { HTML } & \text { HyperText Markup Language } \\ \text { REST } & \text { Representational State Transfer } \\ \text { UI } & \text { User Interface } \\ \text { UX } & \text { User Experience }\end{array}$





\section{Chapter 1 - Introduction}

Applications of geographic information systems (GIS) within historical research are spreading as technology becomes increasingly capable of presenting time in ways relevant to field specific research. Allowing social science practitioners to gain instant access to their data can augment research potential often locked inside previously impenetrable historic census data. Unlocking such data has wide reaching implications in public outreach and edification, especially when expressed cartographically in an interactive web based medium.

Missions were established in California in the late eighteenth century by Spanish colonials. They were intended to be religious centers from which Catholic priests could introduce indigenous tribes already living in California to Spanish religion and custom. Missions are particularly significant to the understanding California history as well as the history of the people who have inhabited the western coast of North America for thousands of years. This project is intended to provide educators and students with an interactive web application representing seven missions under the San Francisco Presidio. This web application will enable the user to explore the relationship between missions and indigenous peoples who lived in what is now known as the San Francisco Bay Area through statistical methodologies and temporal representation.

\subsection{Client}

Dr. James Sandos, Professor of History at the University of Redlands, and Patricia Sandos, historian, sought a GIS application and statistical analysis in order to continue their research concerning the effects of the California mission system on indigenous communities. For their research purposes, the client required spatial analysis of baptismal records from San Francisco Bay Area missions. For outreach purposes, the client also required a web application which would make the data accessible to a large audience of varying age ranges.

It was the client's responsibility to provide Excel tables and previously created geodatabase tables and shapefiles for reference to this project. The majority of data provides census data concerning indigenous individuals as related to baptisms. This includes godparent information, thus linking individuals back to a certain mission. All data have been previously transcribed from hand written records kept by Spanish priests at each mission and then entered into a database. Through multiple meetings with the client, the intention and scope of this project were defined.

\subsection{Problem Statement}

Mission records, while often extremely detailed, do not allow the client to sufficiently visualize and analyze their data. This is because the geographic relationships between individuals, godparents, missions, and tribes, are embedded in the tabular records that do not provide any geographic context. As such, the client sought a way to quantify and spatially visualize the interactions of the mission system with tribes through godparent relationships to baptized individuals. 


\subsection{Proposed Solution}

The following approach was proposed to deliver an interactive geographic web application in addition to statistical analysis results to the client. A period of research, data acquisition and data scrubbing was followed by ANOVA and t-testing on population records and inclusion of the data into a JavaScript web application.

\subsubsection{Goals and Objectives}

The primary goal of this project was to facilitate analysis of Alta California mission records for the client in a way that would allow them to communicate their findings with a broad academic audience. Three objectives were defined to meet this goal.

The first objective was to associate each person with a location represented spatially by points or polygons. Individuals are represented spatially by their original tribal location, which allows the historian to access temporal, age and gender data. Association with baptismal Mission locations allows for analysis of trends.

The second objective was to provide a basis for statistical analysis integral to the examination of the provided baptismal records. Results from such analysis will help the client draw conclusions about indigenous individuals affected by the institution of Spanish Missions as well as communicate known trends which reveal how Spanish and indigenous peoples in the region interacted.. The ability to apply these statistics spatially may also allow the client to identify future research topics.

Access to historical mission census data is paramount to this project. Therefore, the third objective of this project is to provide the client a platform from which the client can spatially interact with their data. Providing charts detailing the statistical trends over time alongside a record search query function will assist the client in communicating their knowledge of the subject matter with other educators, peers and students. This platform will enable the client to communicate their research objectives as well as the importance of historical accuracy in early education programs in California.

\subsubsection{Scope}

This project consisted of three primary components: inclusion of mission data into a geodatabase, statistical analyses, and design and implementation of an interactive web application. Data were received from the client in the form of Microsoft Excel and ArcGIS geodatabase tables. All data were combed through for relevancy to increase processing speeds and incorporated into an ArcGIS file geodatabase. Statistical analyses were run on said data using tools provided within ArcGIS Desktop 10.1. The results of this analysis were then incorporated into the web application, which includes basic analytical and query functions. This final product was intended to facilitate the clients' exploration of California Mission census data and to communicate the results of their research with educators and students.

\subsubsection{Methods}

Various methods and techniques were employed in the implementation of this project. Initially, a literature review was conducted to explore previous research done on this 
topic. From this information, goals and objectives were identified and a scope was set in place. Functional and non-functional requirements were defined during the implementation planning phase.

Data preparation followed the creation of conceptual and logical models aimed at integrating multiple tables from two primary sources into one database. This database was designed to be queried easily by the client.

Statistical analysis was performed on mission outreach population data after defining the client's main study interests. Charts and graphs were created to support the client's research purposes. Analytical results were then represented in an interactive web-based application. The application design included query capabilities as well as inclusion of widgets necessary for accessing mission data.

\subsection{Audience}

This report is intended for use by historians interested in California missions and educators who may be required to include California mission history into their curriculum. GIS professionals wishing to represent historical data on a web based platform might also find this report of some value.

\subsection{Report Overview}

The remainder of this report is divided into six additional chapters. Chapter 2 gives a brief history of the mission system and defines the concept of georepresentation. Project design and statistical analysis is detailed in Chapter 3. Database designs including conceptual and logical models as well as data processing techniques are covered in Chapter 4. Web application implementation is discussed in Chapter 5. The results of population longevity analysis are explored in Chapter 6. Conclusions and possibilities for future work are discussed in Chapter 7. 




\section{Chapter 2 - Background and Literature Review}

This chapter provides a brief overview of the advent of the Spanish mission system in California and previous work concerning mission baptisms in the San Francisco Bay Area. Section 2.1 discusses the general impact of mission implementation on indigenous populations and then baptisms are discussed as the best way to measure such impact. Section 2.2 focuses on georepresentation of indigenous populations by means of baptismal records.

\subsection{Brief Overview of the Spanish Mission System}

Spanish colonists brought the mission system to Alta California in the late eighteenth century. The term Alta California was used by Spanish colonials to refer to the area of land between what is now known as San Diego and Sonoma. The study area for this project focuses on the seven most northerly missions within Alta California, which lie roughly within the San Francisco Bay Area. Mission San Francisco de Asis or Mission Dolores, established on June 26, 1776, was the earliest mission established in the study area. Within the next twenty years, Missions Santa Clara de Asis, Santa Cruz, San Jose and San Juan Bautista were formed. Missions San Rafel Arcangel and San Francisco Solano followed ten years later.

Missions were established not only to provide outposts for Spanish colonists, but to serve as central locations for the dissemination of Eurasian ideals to local indigenous populations. In many cases, priests "were intent not only on bringing the Christian religion to the Indian people, but also on changing their way of life - modifying their economies, personal habits, and thought structures" (Milliken, 2008, p. 30). While such intentions might have initially prompted settlement in Alta California, the stark colonial truth of Spanish governance was soon revealed. Indigenous people who had lived in the area under their own power "were to become the labor force in a new Spanish world... designed to give Spain effective settlements on its northern frontier and to hold the territory against foreign encroachment" (Sandos, 1997, p. 201). These ideals would prove to be disastrous for both Spanish interests and indigenous populations in the region.

In order to understand the impact that the mission system might have had on indigenous populations, it is first necessary to define the societal organization of tribes in the area. On contact, the Spanish priests and other colonists would have found bands or tribes of individuals who spoke a similar language but moved seasonally between one chosen location and another (Skrowronek, 1998). The study area of this project is comprised of individuals representing six prominent language groups (Figure 2.1). Indigenous peoples living within and south of what is now San Francisco would have most likely spoken Ohlone (or Costanoan), while individuals north of the City might have spoken Pomo. Those who lived inland would have spoken largely Miwok, Wappo, or Yokuts. 


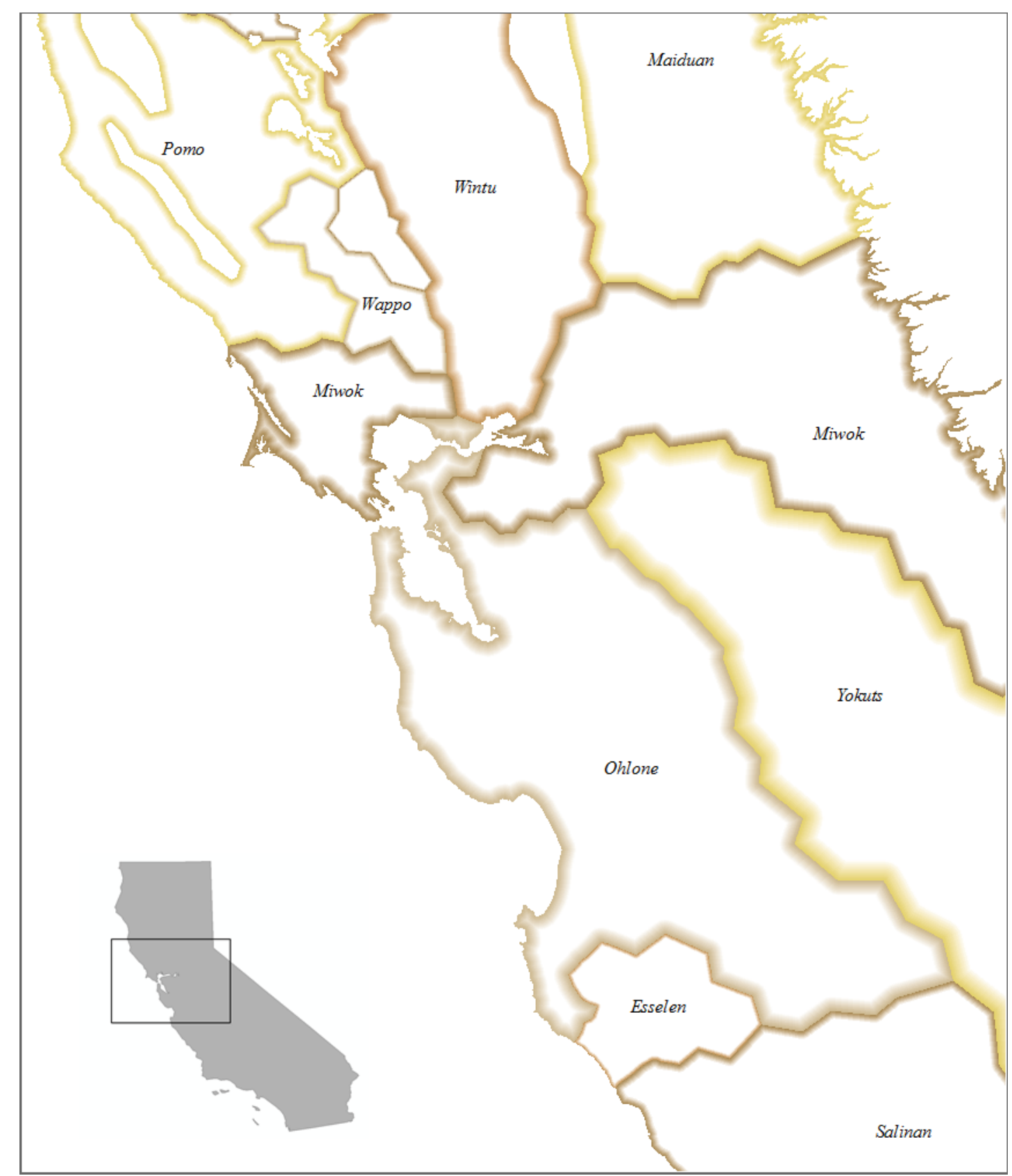

Figure 2.1 Indigenous Language Groups

Grouping by language is one way of understanding what life might have been like for indigenous populations. Skowronek (1998) describes the Ohlone as "semisedentary people" who adapted specific methods to live in the Bay Area. He estimates that the population numbered near ten thousand at contact and divided labor by gender. The Ohlone secured the continued return of plant and animal resources, "through the controlled burning of extensive areas of grass and forested lands to promote the growth of seed bearing annuals that were attractive to both humans and as browse for animal prey," (p. 680). Skowrenek goes on to detail Ohlone social structure. "Women collected [...] materials for basketmaking and their most important vegetal food sources - grass seeds, 
acorns, and a variety of bulbs. Men hunted, fished, and collected shellfish," (p. 680). The population consisted of small groups of men and women who might have organized themselves hierarchically. Further information on tribal structure across Alta California has largely been lost to history due to few records being kept by Spanish colonists in the area (Milliken, 2008).

Sandos and other researchers have asserted that Spanish priests cared very little about how tribes in California were organized (Sandos, 1997), much less about specific spiritual beliefs (Skrowronek, 1998) or subsistence patterns (Peelo, 2009). After a mission location was decided upon, "temporary settlements of the indigenous populations in Alta California were congregated and made into permanent settlements...built by the native populations" (Peelo, 2009, p. 589). Each individual who was to be part of the mission system was baptized. Baptisms were recorded meticulously by the priests within the mission. Compiled baptismal, marriage and death records regarding individuals often include a date of birth, the date an individual was baptized, the godparent, of the baptism, as well as a date of death along with many other notations. This precedent of record keeping inherently imposes Spanish organization onto modern perception of historic indigenous groups.

Baptism was relied upon by Spanish priests as the primary means of incorporation of indigenous individuals into the mission system. The reasons why individuals might have elected to be baptized are multiple and do not exclude forced coercion (Sandos, 1997). Peelo (2009) argues that, "the specific cultures interacting at each mission and a diverse set of factors influencing baptism must be considered individually for each colonial encounter" (p.590). No matter what the impetus was, Peelo asserts that the baptism process had a negative impact on indigenous populations, particularly through the spread of disease (Peelo, 2009). The impact of baptism on tribal populations can most easily be measured by the categorization of indigenous populations by mission affiliation.

While classification of many tribes within a single mission outreach area might not provide necessary insight into the historical lifeway of a culture, it does give some idea as to what life at a particular mission might have been like. When analyzing disease and demographic patterns at Mission Santa Cruz, Jackson (1983) groups populations first by single and then by clusters of geographically nearby missions, which provides a basis for comparison of mission populations. This technique allows him to assert that "the inability of the Indian population to stabilize in the face of high death rates was not unique to Santa Cruz, but occurred in other mission groupings in northwestern New Spain” (p. 33). In fact, what Jackson finds are significant patterns in the rise and fall of populations at various missions, which are dictated specifically by three separate pandemics in 1806 , 1828 and 1838. Historical knowledge such as this combined with baptismal records can lead to a deeper understanding of events within the population of a single or multiple missions.

\subsection{Georepresentation of Indigenous Individuals with GIS}

Geographical placement of individuals provides historians a new depth of understanding of the impacts of the mission system on indigenous populations. Geography enables two dimensions of spatial perception. "Horizontally it is concerned with the flows of people and ideas. Vertically most places can be broken down into increasingly small units to the level of individuals and households that have distinct locations within a place," (Gregory 
\& Ell, 2007, p. 5). Time provides an additional third dimension for understanding temporally dynamic event which is integral to the portrayal of historic events.

Georepresentation is the culmination of horizontal, vertical and temporal spatial perception to represent individuals or events.

Georepresentation of mission data requires the delineation of sometimes ambiguous social boundaries into static spatial boundaries. The boundaries used for this project have been defined previously by Milliken (2008). He divides language groups into smaller tribal areas or rancherías. Milliken's records refer to tribal areas as "rancherías" or "regions" and represent information recorded by the Spanish given by an individual concerning their own origin. Milliken then groups these rancherías into mission outreach areas that represent the influence of each mission. Outreaches are defined by taking into account the origin of each individual baptized at a specific mission. Figure 2.2 shows each mission outreach area addressed in this project. Delineation of mission outreaches allows the ethnohistorian to gain insight into how populations were impacted by each mission and geographers to place individuals spatially, but admittedly does not provide a holistic understanding of cultural norms within a region.
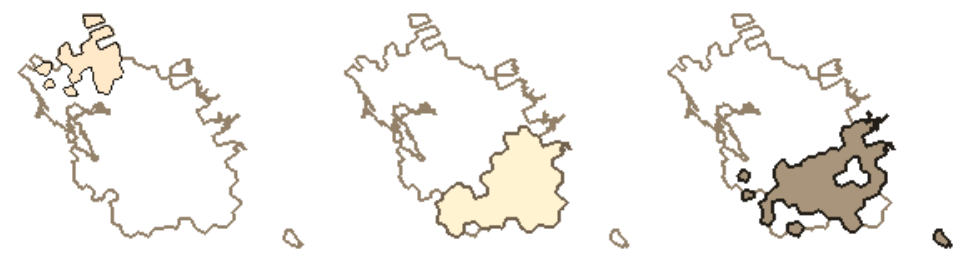

San Francisco Solano San Juan Bautista Santa Cruz
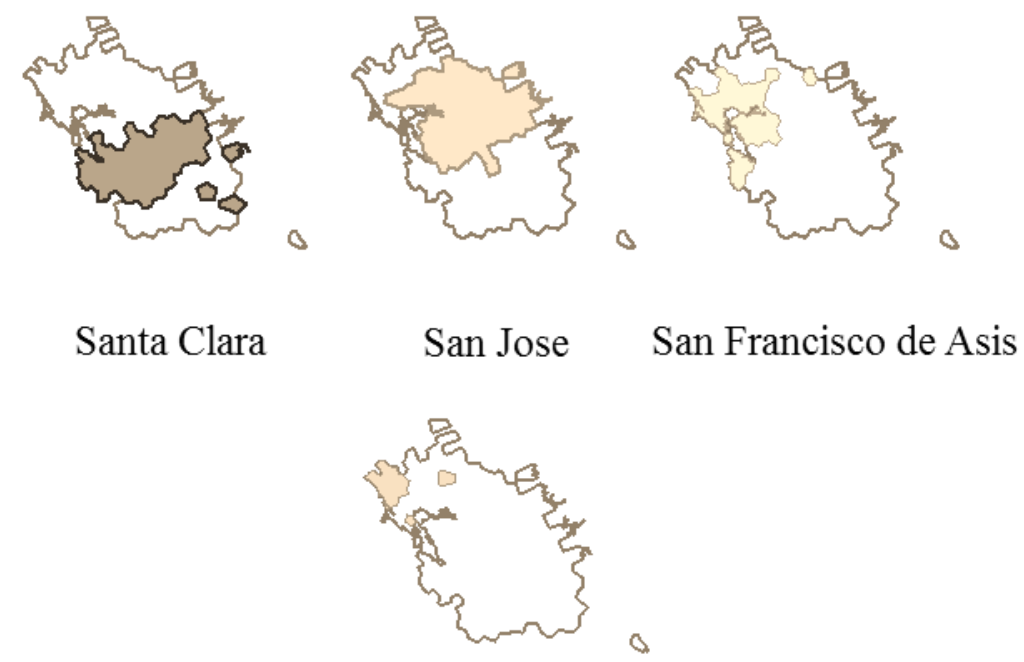

\section{San Rafel Arcangel}

\section{Figure 2.2 Outreach Areas by Mission}

In breaking down the mission system into individual missions, ranchería and individual, Milliken (2008) provided a succinct way to translate mission records into 
geographically meaningful data. Dates of birth, baptism and death contained within the mission records provide the third and equally important temporal component. When baptism progression is dynamically displayed over time, historians may gain better understanding of the spread of the impact of the mission system.

Though a static map has the ability to provide further insight into patterns and interactions between people and places, it does not provide the level of interaction needed to reach many people at one time. Construction of a geographic web application can provide an interactive experience which allows multiple users to visualize historical data that previously has only been represented on paper maps. Ideally, a web application would make way for researchers to access, "dataset-level metadata that describes the spatial extent of the entire dataset, and record-level metadata that describes the spatial extent of each record within a dataset," (Gregory \& Ell, 2007, p. 157). A successful geographic web application would also allow for quantitative if not qualitative research using query functionality.

\subsection{Summary}

Ultimately, successful georepresentation of indigenous individuals requires both a desktop GIS and geographic web application. The former provides access to all data, while the latter may serve as both academic outreach tool for use by those with some previous background knowledge of the mission system or by an historian to quickly access small amounts of data and to see time actualized within a query format. Implementation of both relies upon the geographic understanding already delineated by Milliken and the client in accordance with their previous knowledge of the inner workings of the mission system. With combined knowledge of historic events and geographical boundaries, a GIS may successfully represent interactions between indigenous individuals and Alta California missions. GIS should be viewed as a tool for analysis that fits the researcher's needs, "as long as the research is concerned with information on theme, location, and, if appropriate, time," (Gregory \& Ell, 2007, p. 9). The GIS detailed in this project was designed with the client's research and academic outreach interests in mind. 




\section{Chapter 3 - Systems Analysis and Design}

This chapter will provide a detailed look at the system analysis and design that is at the root of this project. First, the client's problem is revisited. Then functional and nonfunctional requirements integral to defining the scope of this project are detailed. Finally, the system design for this project and implementation of system design and requirements are discussed.

\subsection{Problem Statement}

James and Patricia Sandos required an efficient way to access an immense database which details the interactions between indigenous individuals and Spanish missions in Alta California. Implementation of a geodatabase will allow the client to explore the California mission system through statistical and spatial analyses. A web GIS application will allow the client to communicate information concerning the impacts of Spanish colonialism on historic indigenous communities with students and other scholars.

\subsection{Requirements Analysis}

Functional and non-functional requirements were defined to provide a basis for implementing this project. Functional requirements focus on active functionality with which the user directly interacts. Non-functional requirements describe the inner workings of a system which are integral to the system's success. Table 3-1 provides a summary of functional and non-functional requirements for this project, which will be further explained below.

\section{Table 3-1. Functional and Non-Functional Requirements}

\begin{tabular}{|l|l|}
\hline Requirements & \\
\hline Functional & $\begin{array}{l}\text { The web application shall provide a function which } \\
\text { displays population statistics. }\end{array}$ \\
\cline { 2 - 2 } & $\begin{array}{l}\text { The web application shall provide a function which } \\
\text { displays population change over time. }\end{array}$ \\
\cline { 2 - 2 } & $\begin{array}{l}\text { The web application shall provide a function which } \\
\text { allows the user to query godparent and individual } \\
\text { records. }\end{array}$ \\
\cline { 2 - 2 } & $\begin{array}{l}\text { The web application shall allow the user to view San } \\
\text { Francisco Bay Area mission locations \& outreach } \\
\text { zones spatially. }\end{array}$ \\
\hline Non-Functional & ArcGIS API for JavaScript \\
\cline { 2 - 2 } & ArcGIS 10.1 \\
\cline { 2 - 2 } & ArcGIS File geodatabase \\
\cline { 2 - 2 } & ArcGIS Web Server \\
\cline { 2 - 2 } & SPSS \\
\hline
\end{tabular}




\subsubsection{Functional Requirements}

Functional requirements of this project include implementation of an interactive web application and incorporation of statistical analysis results within the web application to examine the relationship between geographical and environmental factors and longevity of individuals baptized at each mission. The web application chosen to represent the data was implemented with ArcGIS API for JavaScript. Four distinct interactive functions were incorporated into the user interface that allows the client to view their data in different ways. The first displays descriptive statistics concerning mission populations. The second shows population change over time by using a time slider function. The third allows the user to query tables by godparent, region and date of baptism. The fourth allows the user to view mission locations and outreach zones.

\subsubsection{Non-Functional Requirements}

Non-functional requirements of the system address accessibility and database function (Table 3-1). The mission database was designed to support the inclusion of additional data by the client so that updates could be made easily. The client is responsible for making updates at a pace that fits their schedule and research requirements. The system was designed using ArcGIS 10.1 and file geodatabases were created to house data, which can be accessed in ArcMap 10.1.

ArcGIS for Server was then used to serve data from the file geodatabase to a web application. The web application was built with ArcGIS API for JavaScript to preserve the longevity and malleability of the application through future updates of online coding languages such as HTML and CSS. The interactive web application was required by the client to be accessible to a wide age range to promote use for educational purposes.

\subsection{System Design}

Functional and non-functional requirements as discussed with the client were the foundation for the system design. The system architecture and design of the web application interface is detailed in this section. The final product of this project includes one normalized ArcGIS file geodatabase and one interactive online web application. The web application includes functions of query, chart creation, and temporal representation of the data. Figure 3.1 shows the general system design. 


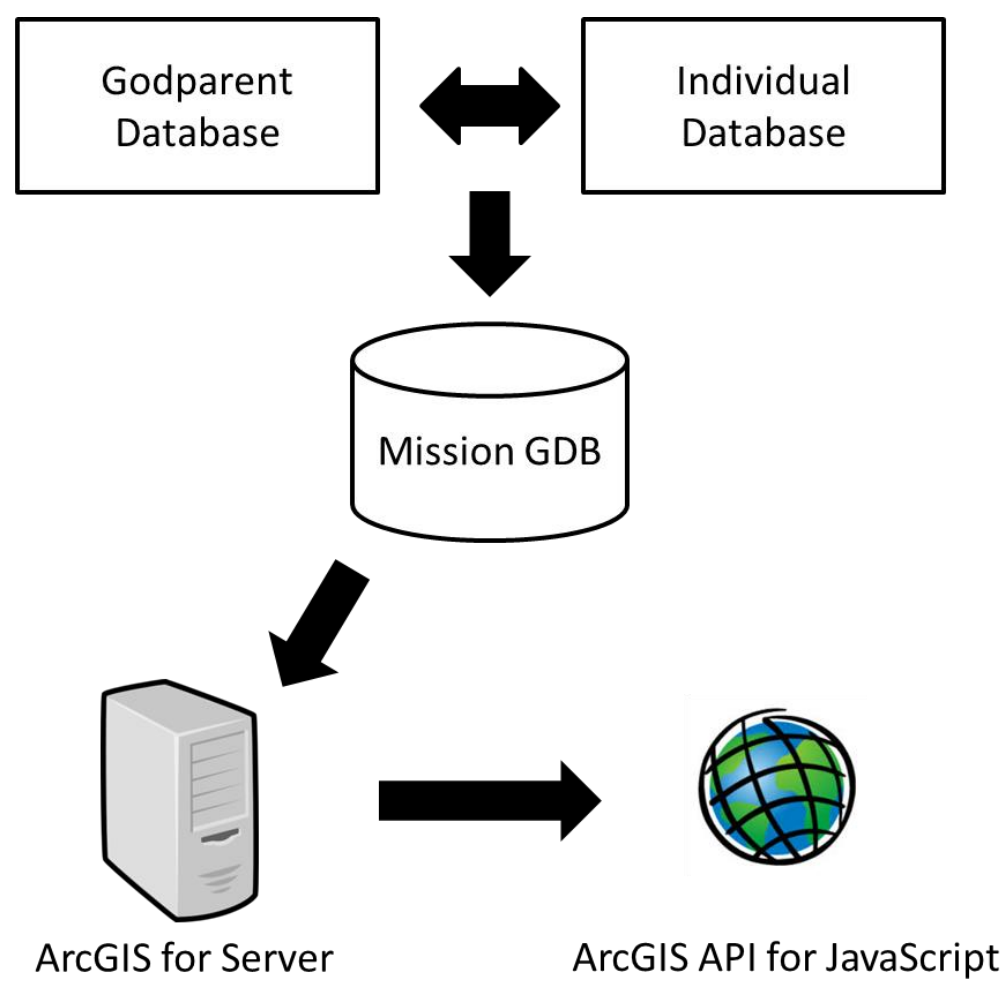

Figure 3.1 System Design

\subsubsection{Functionality of the Web Application}

The primary function required by the client was a platform from which they could gain a more in depth understanding of mission records. This required an intuitive web interface design, which would ask for few user inputs to provide an effective level of interaction. The web application was also designed to show relationships between baptized individuals, their birthplace, and date of baptism by graphic representation of these relationships on a base map showing their origins and mission locations.

\subsubsection{System Interface}

Due to the educational nature that the client envisioned for the web application, the ArcGIS API for JavaScript platform was chosen. This platform supports widgets which provide the user with a more in depth understanding of their data through interactive exploration of spatial data. For example, one widget is capable of displaying charts when each mission is selected. Mission records may also be queried to identify baptized individuals and the godparents who witnessed their baptism within a region. Last, a time slider widget was considered, which animates the changes in Mission outreach by year by location of baptized individuals. The decision was made to show statistics and spatial visualizations interactively in the web application in order to appeal to a wider audience of various age groups and experience levels. 


\subsection{Project Plan}

The implementation plan of this project was developed over a period of several weeks and included many meetings with the client. During this time, a scope was developed and risks were identified. Implementation objectives were set and critical success factors were defined. The implementation of this project was defined by a waterfall life cycle framework. The waterfall framework was chosen to accommodate four primary tasks within a short period of time.

The first task was to acquire and normalize all data and feature layers or shapefiles from the client. This data was subsequently entered into a file geodatabase. During the preparation of data for statistical analysis, the project area was expanded to include seven mission outreach areas, which provided a larger basis for comparison. All data was supplied or approved by the client. Data was then incorporated into the project according to guidelines previously defined for the initial dataset. Samples of the data were reviewed to ensure adherence to these guidelines.

The second task was conducting statistical analysis and designing the required web application. Web application design went through much iteration to incorporate functionality in a way that would be accessible to many users. While most functions succeeded in sustaining an intuitive user interface, some were modified to better incorporate information in an even more accessible way.

The third task involved connecting data within a geodatabase on ArcGIS for Desktop to ArcGIS for Server, which was then served to the JavaScript API web application. Statistical analysis was performed in SPSS during this time. The web application was designed, and the figures produced to show the results of statistical analysis were incorporated into the application along with additional functions.

The fourth and final task was to present the client with the web application and cleaned data within a file geodatabase.

This implementation of this project encountered several changes over the course of the program. These changes occurred primarily due to the focusing of the client's research initiatives to ask a spatial as well as an analytical question and the decision to incorporate a larger population for statistical analysis. Both factors were incorporated into risk analysis, and were identified as possible causes for scope creep which would have inhibited the finalization of this project. These risks were mitigated by redefining the scope to include statistical analysis and figures as opposed to a tool designed to run statistical processes on mission population data. This decision was supported by the ephemeral yet static nature of historical census data, as discussed in Chapter 4.

\subsection{Summary}

System analysis and design provided a structure for the implementation of the system and project development. During this process, requirements were defined and interface and system design were described. The final system was envisioned and steps were taken to identify risks and mitigation techniques were detailed. Scope was reinforced and further defined as scope creep and slight changes in implementation were accommodated. Chapter 4 will further discuss the data and database design. 



\section{Chapter 4 - Database Design}

This chapter discusses the design of conceptual and logical data models. The conceptual data model of this project considers the major elements included in the mission system and their relationships, while the logical data model details the structure of the geodatabase and the attributes contained within each element. Following presentation of the data models are detailed discussions on data sources, collection methods, and data scrubbing.

\subsection{Conceptual Data Model}

The conceptual model of this project is at the root of understanding all of the mission system components that interacted within Alta California from 1787 - 1840. Its purpose is to show relationships between missions, mission "outreaches" and individuals. Figure 4.1 illustrates the conceptual model.

The study area includes seven missions. Each mission acted as a central place of baptism for all individuals in the outreach area of that mission. The outreach area of the mission consisted of loosely bounded tribal areas, or rancherías. The people who lived and interacted within a mission can be divided into tribal and mission born classifications. The tribal class indicates that an individual was born (or originated) in a ranchería; while the mission class denotes that an individual was born at a mission. This classification was bred out of the client's interest in comparing longevity of tribal born individuals with mission born individuals.

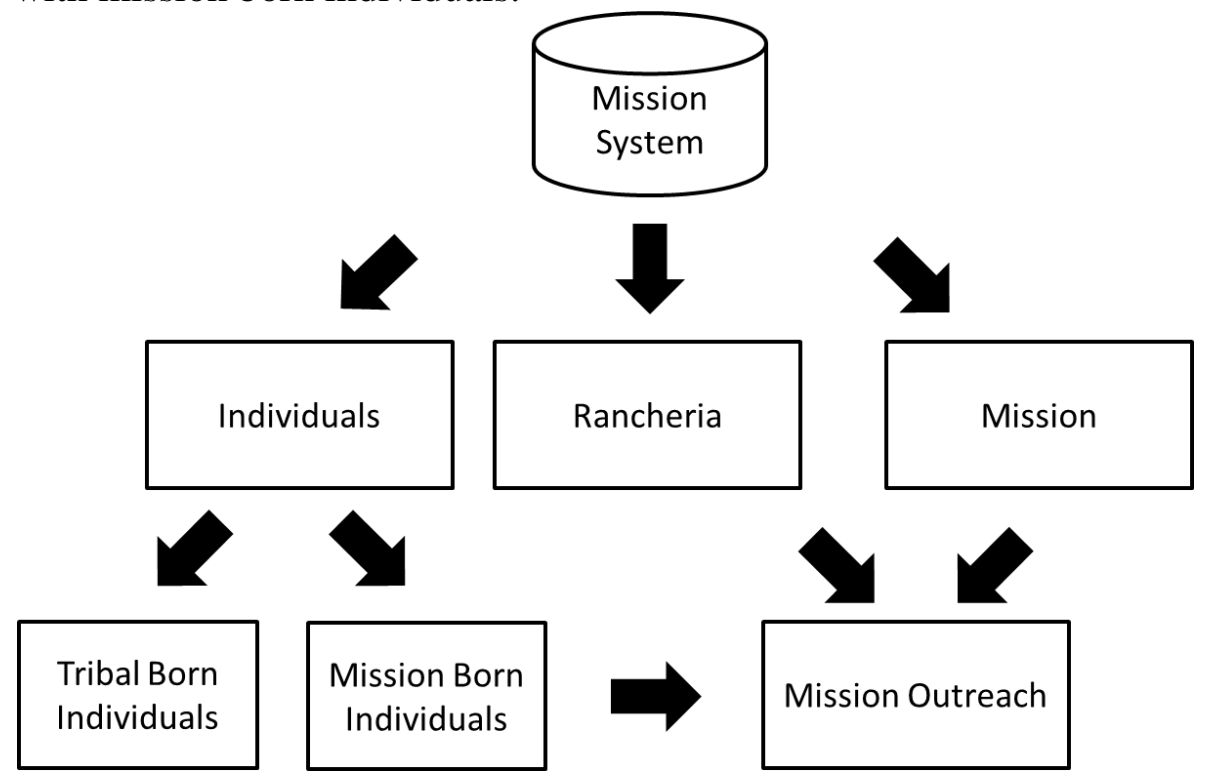

Figure 4.1 Conceptual Data Model

\subsection{Logical Data Model}

The logical data model for this project was implemented with an esri file geodatabase (Figure 4.2). 


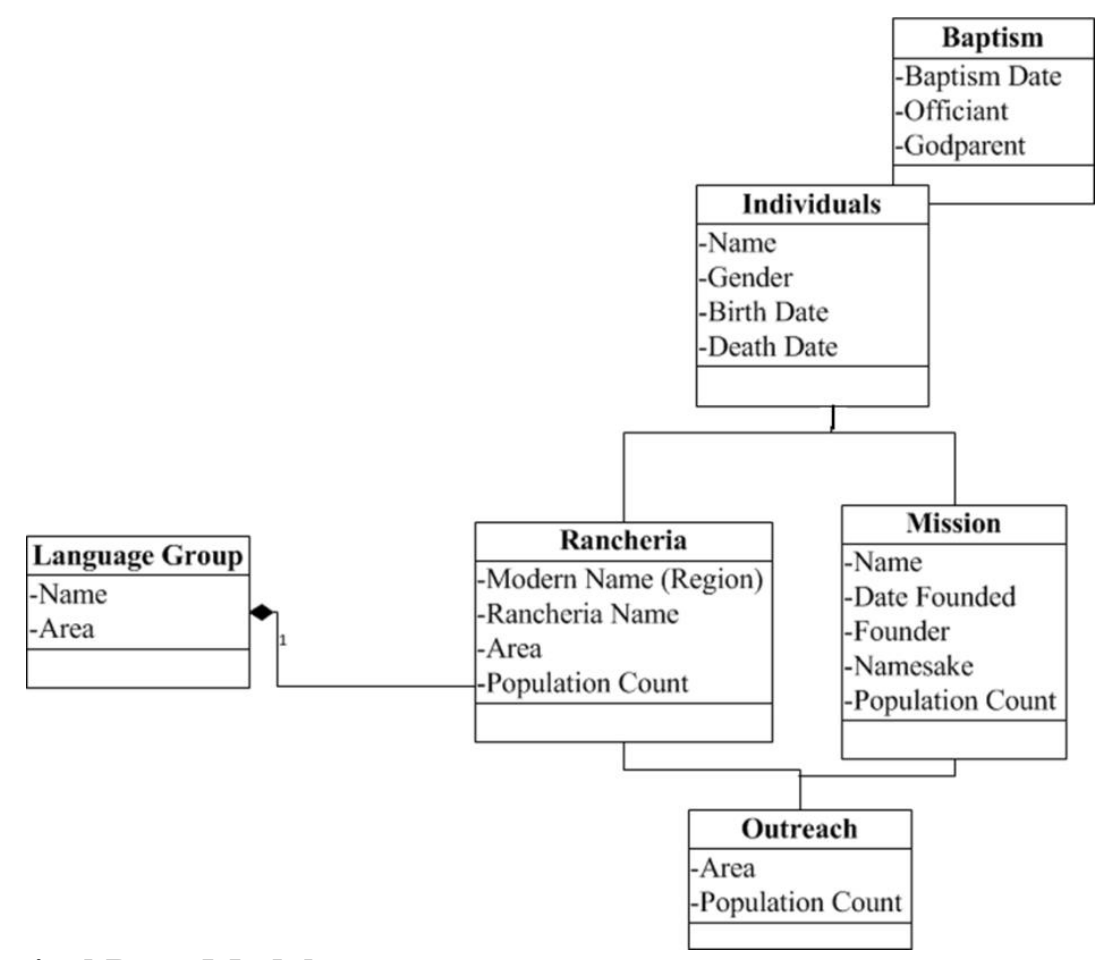

Figure 4.2 Logical Data Model

The final MissionGIS geodatabase consists of five feature classes: Individuals, Ranchería, Mission, Outreach and Language Group. Individuals are represented by points in the Individuals feature class. Rancherías are represented by Thiessen polygons in the Rancheria feature class. Missions are represented by points in the Mission feature class. Outreach and Language Group feature classes are represented by polygons.

The Individuals feature class represents individuals who were baptized by Spanish priests at seven missions in Alta California from 1778 through the year 1840, which was indicated by the client as the beginning of Spanish colonial decline in the region. Each individual was assigned a pair of coordinates that describe what ranchería or mission the individual is from. The location was created by joining the attribute "region," which represents the modern name for a ranchería where an individual originated, with center points from the ranchería Thiessen polygon feature class provided by the client. Spatial representation of individuals allowed for the outreach area of a mission to be defined. Individuals were broken into two general groupings: those who were born and baptized at one of the seven missions, and those who were born on rancherías and later baptized at one of the seven missions. This classification is represented by the attribute OriginClass, which is binary, where mission origin is 0 and tribal origin is 1 . Individuals are then differentiated by gender. Thus, the attribute GenderBinomial was used, where 0 indicates male and 1 indicates female. Further attributes were added to the Individuals feature class for analysis purposes and are explained in Section 4.4.

While the Individuals feature class represents all baptized individuals that met criteria for geospatial and statistical analysis, this feature class does not fully represent the origin and relationship with missions of the individuals themselves. All individuals belong to a language group, which is composed of multiple rancherías. Mission affiliation 
of individuals within ranchería informs the mission outreach, which, in all cases, overlap with at least one other mission outreach.

\subsection{Data Sources}

The data pertaining to individuals used in this project came from two databases. One database primarily represents godparents, but also contains pertinent dates related to individual baptisms. The other database focuses on inferred and actual details relating primarily to tribal individuals. Both databases are interpretations of one set of Spanish language hand-written records kept by mission priests. The two databases were joined together using baptismal identification numbers assigned by mission priests.

The decision to join individuals and godparents databases on baptismal identification number was informed by the client's previous work with the Redlands Institute. This work focused on creating a query tool that allowed the client to access their data on mission populations.

It is particularly important for the user to keep the historic nature of this data in mind. Even at best, hand written records can be unreliable. When interpreted by scholars hundreds of years after recordation, the data become even more susceptible to individual interpretation. That is to say, the data presented is a representation of an historical event and should be viewed as a relevant yet auxiliary means for understanding the past. Therefore, a loose database design is necessary to allow for the fullest range of data exploration on the part of the user. Particular care was taken to represent categories of interest delineated by the client, and to allow them access to the data in the way most logical for them.

Polygon shapefiles representing indigenous language groups, ranchería boundaries, and mission locations were provided by the client.

\subsection{Data Scrubbing and Loading}

Extensive data scrubbing was employed on the joined databases to conform to the requirements of this project. Statistical analysis and web application required only attributes related to date of birth, date of baptism, date of death, name, gender, baptismal ID, origin or region, and mission where the baptism was held. A few additional attributes were kept to assist the client in accessing their data. These attributes included baptismal witness, or godparent related fields as well as those that reflected language and ethnicity.

In addition to general table preparation and cleaning, all layers were clipped to the extent of the study area. All layers were projected in NAD 83 Zone 10. For the final presentation of mission outreach areas, rancherías were merged together.

Attributes regarding baptismal mission and age lived after baptism were added to the Individuals feature class. The mission where the baptism of an individual occurred is indicated in the attribute MissionClass and directly reflects the mission name and identification code that was previously defined. The codes and classes for each of the seven missions within the study area are listed in Table 4-1. 
Table 4-1. Mission Codes and Numerical Classifications

\begin{tabular}{|l|l|l|}
\hline Mission & Code & Class \\
\hline Santa Clara de Asis & CL & 1 \\
Santa Cruz & CR & \\
San Francisco de Asis & FR & 2 \\
San Francisco Solano & FS & 3 \\
San Juan Bautista & JB & \\
San Jose & JO & 4 \\
San Rafael Arcangel & RA & 5 \\
\hline
\end{tabular}

Each individual has been assigned a unique identifier, attribute BapID, which combines the mission code detailed in the figure above followed by a numerical value. In accordance with the client's research scope, all individuals have also been calculated by how many years each lived after being baptized. The attribute YearLived indicates this value, while the attribute BaptAgeClass indicates the age of the individual in question when baptized, organized into six ordinal categories (Table 4-2). The attribute DeathAgeClass uses the same categories, but as related to age at death.

\section{Table 4-2. Classification of Age at Baptism}

\begin{tabular}{|l|l|}
\hline Time Category & Class \\
\hline Less than 6 months & 1 \\
6 months to 1 year & 2 \\
1-5 years & 3 \\
6-10 years & 4 \\
11-15 years & 5 \\
Over 16 years & 6 \\
\hline
\end{tabular}

Additional attributes of the original databases were preserved to allow the client to query by individual name, Godparent name, individual origin and specific birth, death and baptism dates. The attributes Egos_Spanish_Name, Egos_Native_Name and Egos_Surname, Spanname and Nativename hold baptized individuals name information. Attributes Godparents_Name and Godparent_Type indicate the name of the godparent and whether they were male or female (Padrino or Madrina). All relevant date attributes relating to individuals consist of DateBap, AgeBap, BAPTYEAR, BRTHYEAR, YEARDTH, and DEATHAGE. The previously mentioned attribute AgeClass was calculated by taking the difference between BAPTYEAR and YEARDTH. The attribute AgeLVL was used in the event that the longevity of an individual fell below one year. Any redundancy was intentionally preserved due to different formatting between data sets and specific meaning to the client. 


\subsection{Summary}

In this chapter, the conceptual and logical data models were formed. The relationship between individuals, rancherías, missions, mission outreaches and language groups were discussed. Finally, changes to the data were described and attributes added for geospatial or analytical purposes were defined. Chapter 5 describes how these prepared data were applied to project implementation. 



\section{Chapter 5 - Web Application Implementation}

In this chapter, methodology and workflows integral to the success of graphically representing the previously detailed mission data will be described (Section 5.1). Section 5.2 focuses on the functionality implemented in the web application itself, while Section 5.3 presents a use case.

\subsection{ArcGIS Desktop Application}

After preparation of the Individual, Mission and Ranchería feature classes, the data were structured to reflect a simplistic, logical database design in ArcGIS 10.1, as shown in Figure 5.1.

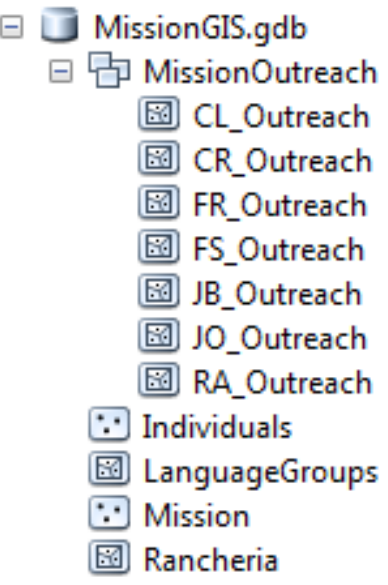

Figure 5.1 MissionGIS File Database

Various modifications to the three feature classes took place to allow for meaningful spatial representation on the web. The Individuals point feature class was assigned coordinates corresponding to ranchería Thiessen polygons. In order to create the outreach of each mission, individual missions were selected by attribute from the Individuals feature class and then were spatially joined to the ranchería Thiessen polygon feature class. Because outreaches overlapped among the missions, an iterative join process between points representing individuals and separate outreach polygons was necessary for accurate representation. After all outreaches were defined as a series of polygons representing individual rancherías, these polygons were then merged to reflect a one to one relationship between mission and outreach. An example of the final output from this operation can be seen in Figure 5.2, which shows the population density for each ranchería. This figure was created by summarizing the "region" field of the Individuals layer, then joining the summary table to the "region" field of the Rancheria polygon layer and symbolizing by the region count with graduated symbols. 


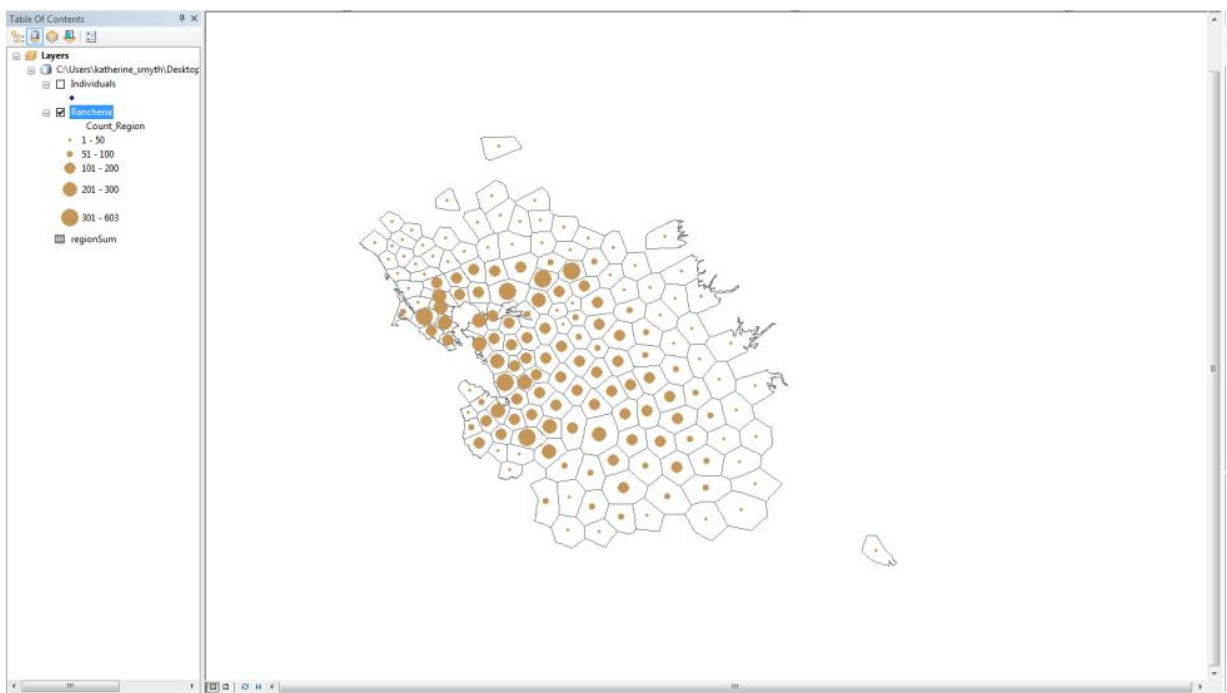

Figure 5.2 ArcGIS Data Analysis Capability (Population Density)

Four fields were then added to the mission feature class which were used to contain population counts of mission born individuals to tribal born individuals as well as mission born versus tribal born gender ratios. Symbology previously used by the client was also assigned to the mission feature class for cartographic design purposes.

In preparation for the web application, separate feature services were published from Mission, Individual, Ranchería and Outreach feature classes within ArcGIS. The decision was made to publish each feature class individually for ease of access. ArcGIS for Server was used to manage how feature classes were served, while ArcGIS Server REST API services were used to allow access to published feature services within the application itself. These services allow for ArcGIS data to be served from ArcGIS Desktop to a designated ArcGIS server.

While platforms such as Flex and Silverlight were available at the time of this project, ArcGIS API for JavaScript was chosen for its current relevance. ArcGIS JavaScript API offers the most programmatic flexibility for use in conjunction with ArcGIS Server feature services. Even though JavaScript is the primary language used within the API, the code also allows for HTML body definition and CSS design, which augments the longevity of the code.

The web application developed in this project was primarily written using JavaScript, HTML, CSS and Dojo. While the application design elements are dictated by HTML and CSS code, the functional properties are written in JavaScript and augmented by Dojo functions and subsidiary dijits (Dojo widgets). Many samples from the ArcGIS API for JavaScript developer's page were referenced or adapted for use in this application. All code was written or modified initially in Notepad++ and then brought into Aptana Studio 3 for final formatting. Debugging was performed in Firefox using the Firebug add-on. All four of these software packages are open source and can be downloaded for free. 


\subsection{Web Application Development}

The primary objective of web application implementation was to successfully present an historical dataset to students, scholars and researchers of different ages. A philosophy of simplicity was applied throughout the design and implementation process. This philosophy is reflected not only in the simple workflow and data structure employed as a foundation for the application, but also in the choice of languages used to program the application in addition to the actual concept and design of the final product. Four primary functionalities were implemented within this web application: dynamic toggle functionality of each mission outreach, a search box supported by query language, dynamic time representation and popups containing information and descriptive statistics of each mission.

\subsubsection{Web Application User Interface}

The user interface for this web application was designed for the incorporation of research objectives and ease of access for a varied audience of students, scholars and historians. Initial design elements were modified to reflect the incorporation and exclusion of functionalities that promoted these objectives. Figure 5.3 shows the user interface as seen when the webpage when opened.

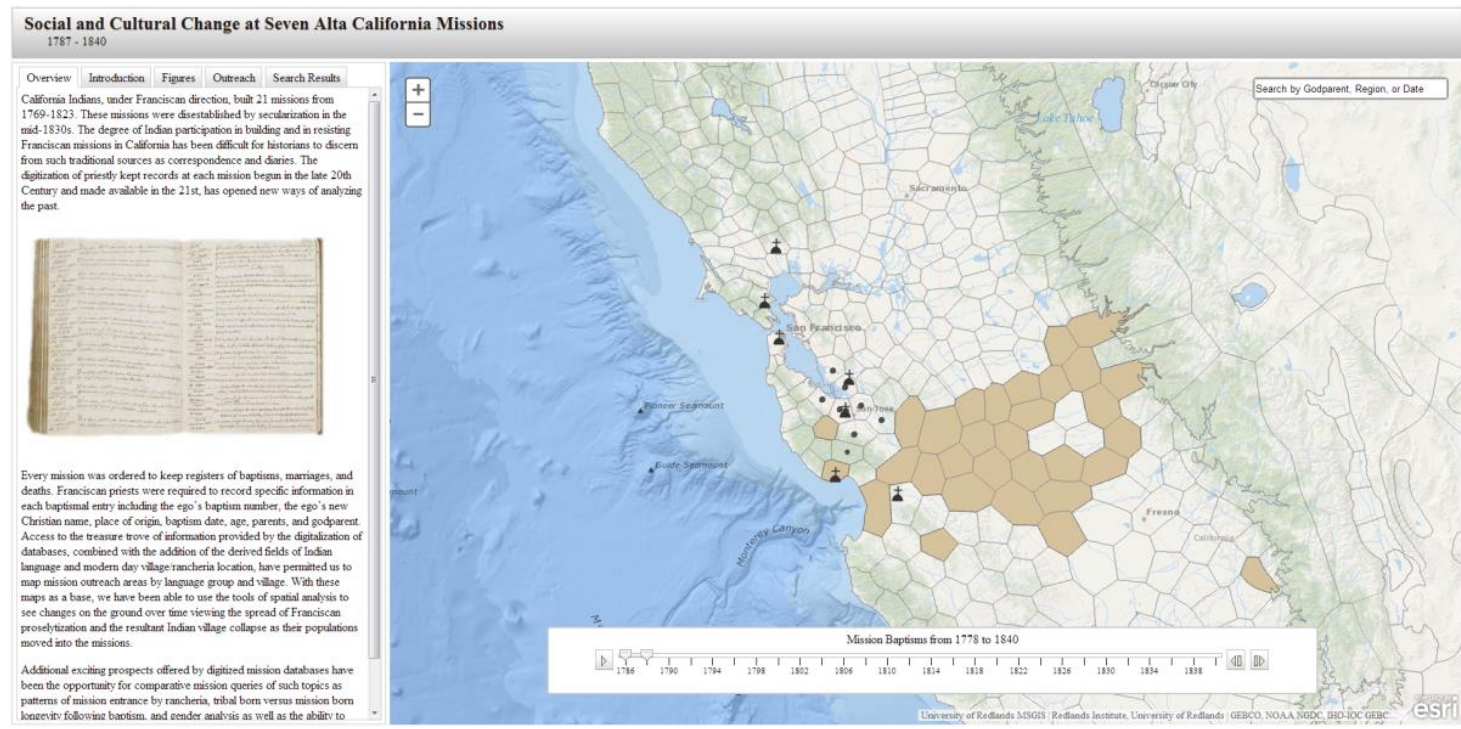

Figure 5.3 User Interface Layout

This interface exhibits a tabbed sidebar on the left of the page, time slider to the bottom of the page and a search bar in the upper right hand corner of the page. The following sections detail how each function was created and explains the intended use.

\subsubsection{Tabbed Sidebar}

The tabbed sidebar allows the user to interact with individual, mission and mission outreach data. The tab container itself was created using code in HTML <div> format within the body section. It contains five functional tabs: Overview, Introduction, Figures, 
Outreach and Search Results (Figure 5.4). The content of each tab was assigned an identification name within the script which allows the function to be tied directly to the $<$ div>. This approach lends itself to faster processing speeds and quicker loading times, as opposed to the other programmatic approach where tabs are also defined in the script.

\section{\begin{tabular}{l|l|l|l|l} 
Overview & Introduction & Figures & Outreach & Search Results
\end{tabular}}

\section{Figure 5.4 Tabbed Sidebar User Interface}

The first tab, "Overview", explains the impetus behind this project, and how it fits in to the larger scope of the client's research. The text itself was contributed by the client (Appendix A). This tab also contains an image of a baptismal record which is hyperlinked to the Santa Clara University archive of scanned mission baptismal records (Collections). The second tab, "Introduction", provides the user with an overview of the functionality within the site (Figure 5.5).

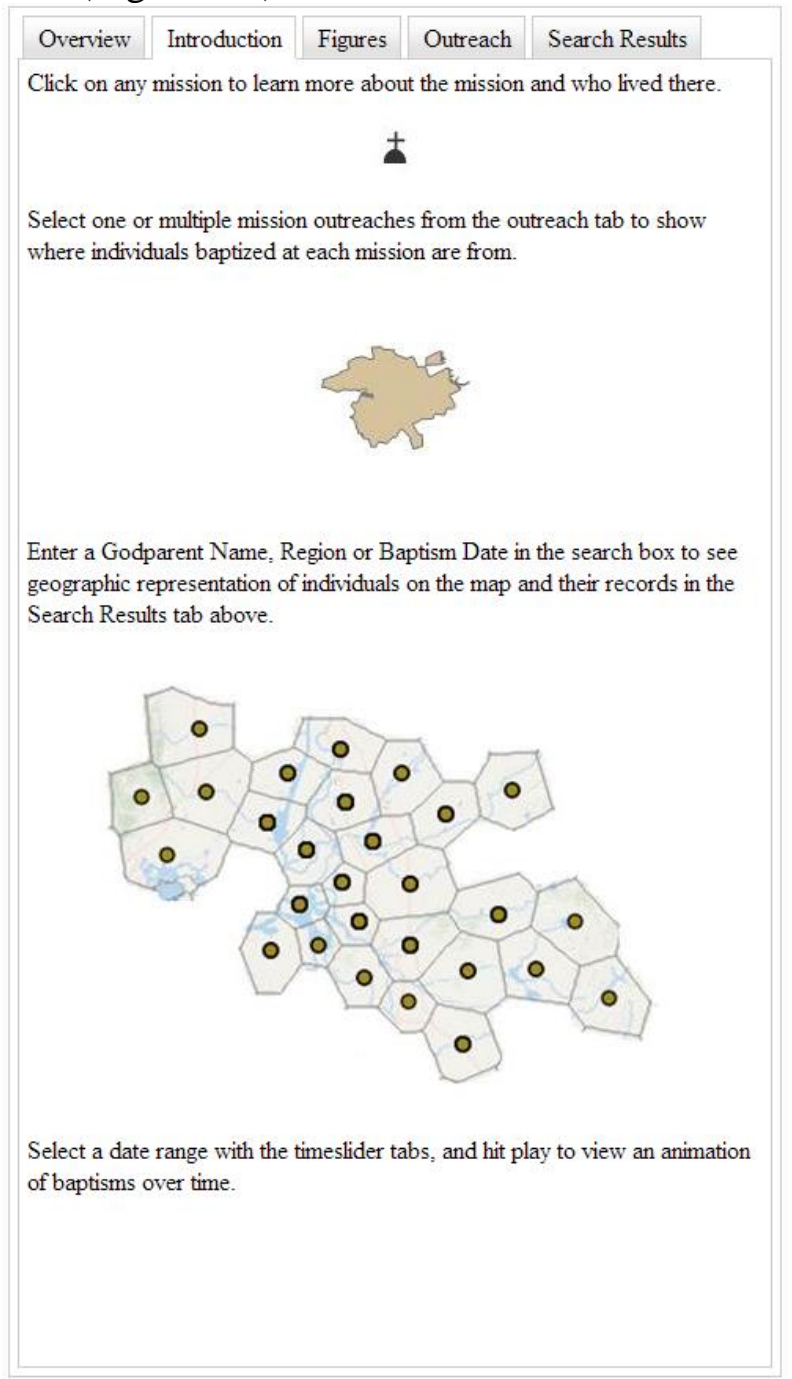

Figure 5.5 Introduction Tab 
The third tab, "Figures", contains three static figures representing results of statistical analysis, including population density, population by mission, and number of tribal and mission baptisms by mission (Figure 5.6). A purposeful decision was made to provide the user with an overview of the study population within this tab. Further statistical analysis was performed on mission populations and will be detailed in Chapter 6 .

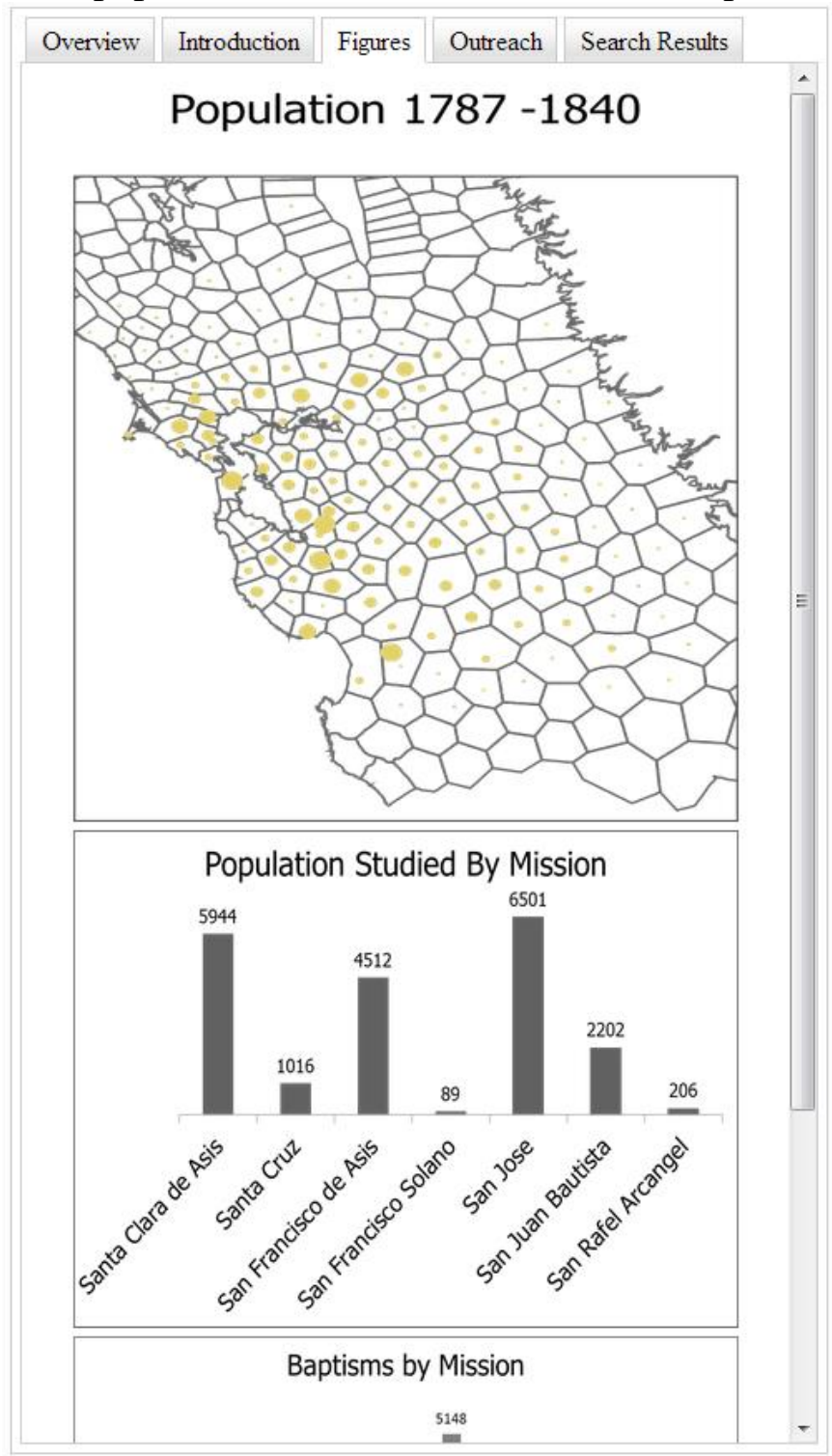

Figure 5.6 Figures Tab

The fourth tab, "Outreach", contains seven checkboxes, which allow for the outreach of each mission to be toggled on and off. Figure 5.7 shows an example of the outreach area of Mission San Cruz. This allows the user to visually compare outreach areas of one or more missions. When combined with the search and time slider functionalities detailed below, outreach becomes a powerful way to give context to an ephemerally distributed population. 


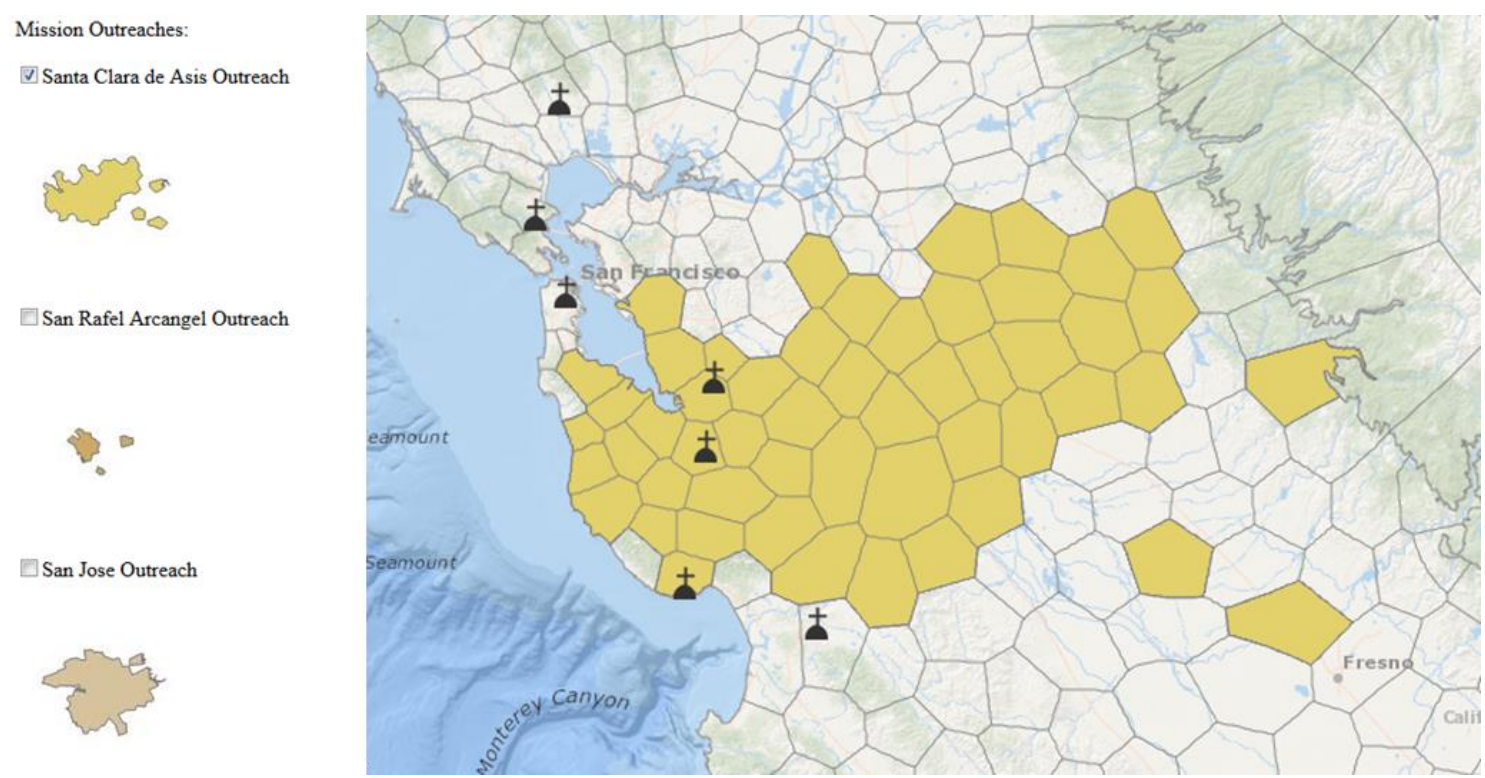

Figure 5.7 Mission Outreach Checkbox Example and Result on Map

The fifth tab, "Search Results", displays the results from the search box in the upper right hand corner of the application.

\subsubsection{Search Functionality}

Search functionality allows the user to query the Individuals feature layer. An underlying query structure was created in JavaScript to allow text or numerical values representing godparent name, region or baptismal year to be entered into the search box. This functionality relies on search box capabilities included in JavaScript as well as CSS code to design the box itself. The query itself was written in SQL language to incorporate all three attributes to be queried. It should be noted that this approach may cause duplicate records if similarities in naming conventions exist. After a user enters one of the three query fields into the search box, graphic points are added to the map via a for loop which indicates that each point should be added if a value is greater than zero, reaching to infinity. Simultaneously, a grid is populated in the "Search Results" tab of the left hand sidebar by an array that follows the previously mentioned for loop, Figure 5.8 shows the search box location with geographic representation of individuals and tabular results. It should be noted that the grid itself is created at the beginning of the script, which allows the structure of the grid to show first on load. Five pertinent fields were identified to fill the grid: BaptID, Godparents_Name (GP Name), Span_name (Name), OriginStandard (Origin) and BAPTYEAR (BaptYear). Every time new input is entered into the search box and enter is pressed, new graphics are placed on the map as new fields are placed in the grid. 


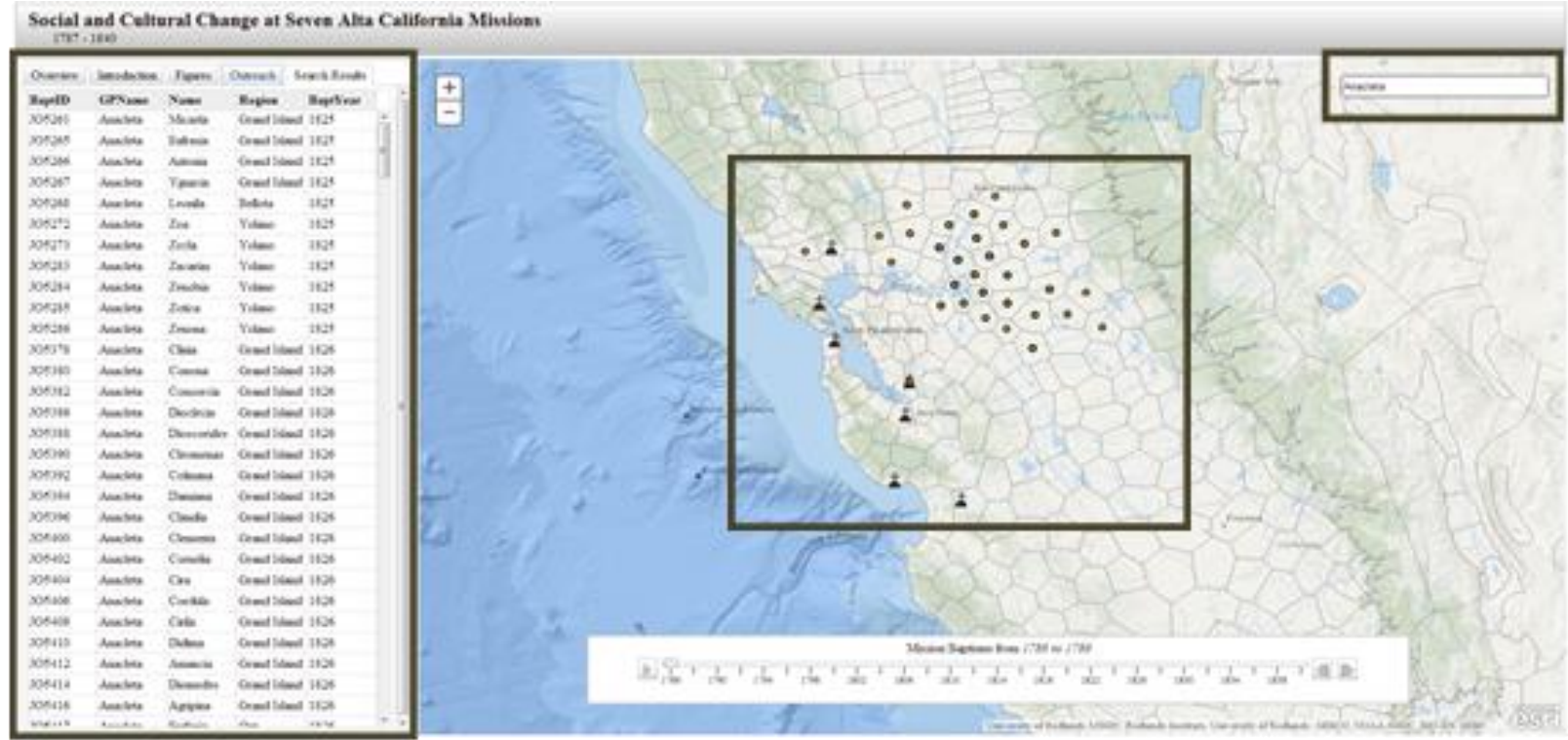

Figure 5.8 Search Box, Graphic Results on Map and Grid

\subsubsection{Dynamic Time Representation}

The time slider function allows the user to visualize the spread of points representing individuals by the year that they were baptized. One can interact with the slider in two ways: by setting a date range of interest, which is reflected in the title and by pressing the play button, which adds points to the map signifying the rancherias of individuals selected within the range chosen (Figure 5.9). Within the code, the time slider connects to a separate rendering of the Individuals layer as a dynamic map service, which enables querying by attribute and time range.

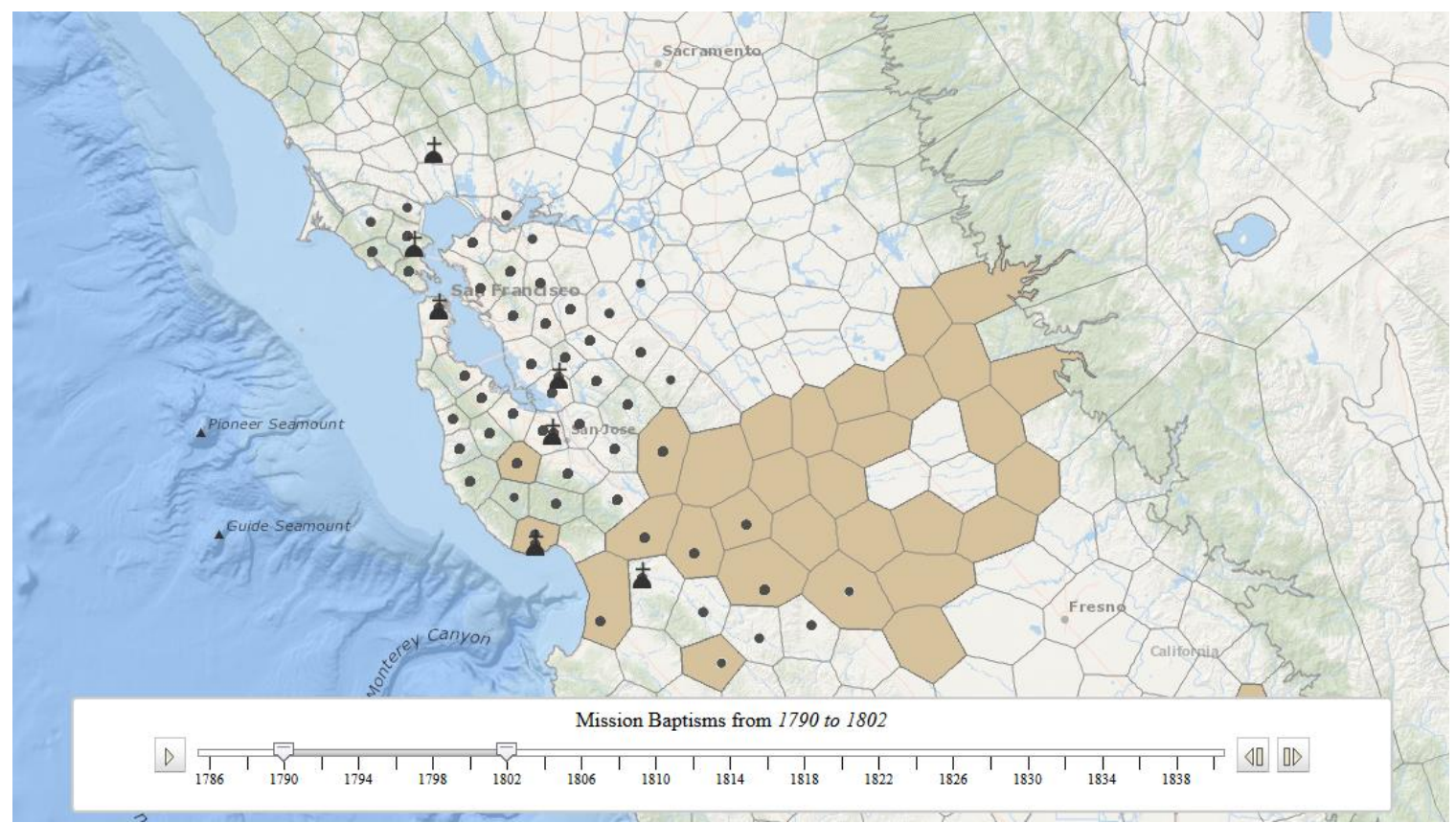

Figure 5.9 Time Slider with Defined Range and Results 


\subsubsection{Popup Functionality with Descriptive Statistics}

The pop up functionality allows the user to click on any mission icon to gain more understanding of social dynamics within the mission outreach. When the user clicks on the mission icon, a pop up with three tabs appears. The first tab, "Details", contains text information about when the mission was founded and who founded it. The second tab, "Origin", displays an interactive pie chart showing the ratio of baptized individuals who were of mission origin to those who were of tribal origin. The third tab, "Gender", displays an interactive pie chart showing the ratio of baptized males to females. The interface for all three tabs is shown in Figure 5.10.
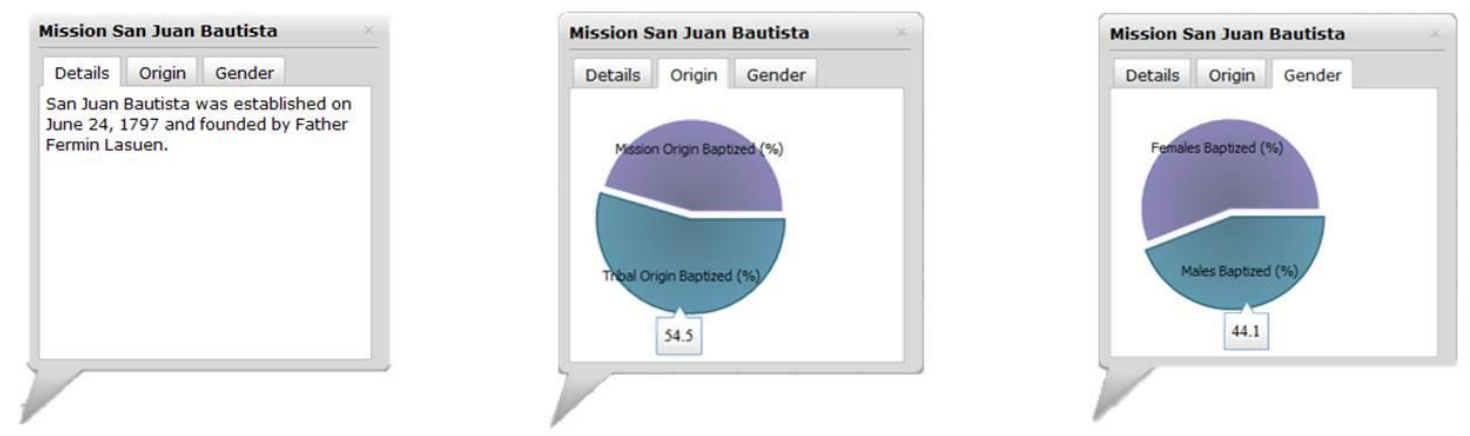

\section{Figure 5.10 Mission Popup Info Window}

The data for all tabs comes from the mission map service. Descriptive statistics are represented by total populations calculated from the individuals layer and then added to the missions layer as four additional fields as mentioned in Section 5.1. The popup itself is a DojoX widget that relies on DojoX chart themes for graphic representation. Attribute fields from the mission layer are divided by total population count within a dojo series command which allows each percentage to be calculated according to mission. The separate tabs containing text and pie charts are programmed directly into the DojoX widget framework.

\subsection{Use Case}

The web application was built to be instantly approachable and to provide a basic level of interaction between the user and the user interface (UI). The user experience (UX) was intended to appeal to an academic audience, whether that is a fourth grader in California or an experienced historian. An interactive UX design led to the implementation of the functionality discussed above.

The first feature that the user will notice when opening the application will be the esri Ocean basemap. This basemap was chosen for its appealing colors and subdued landform color palette and terrain textures. Four layers of ArcGIS based symbology lie on top of the map on open: points representing time slider results, missions, one mission outreach (Santa Cruz) and a static rancheria polygon layer. The opening screen is shown in Figure 5.11. The tab container lies to the left and is open to the first tab, "Overview" which contains text written by James and Patricia Sandos (Appendix A). This tab also contains an image of an historic baptismal record linked by href or hyperlink to the 
University of Santa Clara's collection of scanned baptismal records. The user knows that this is a link because the cursor changes from a mouse to a hand when moused over.

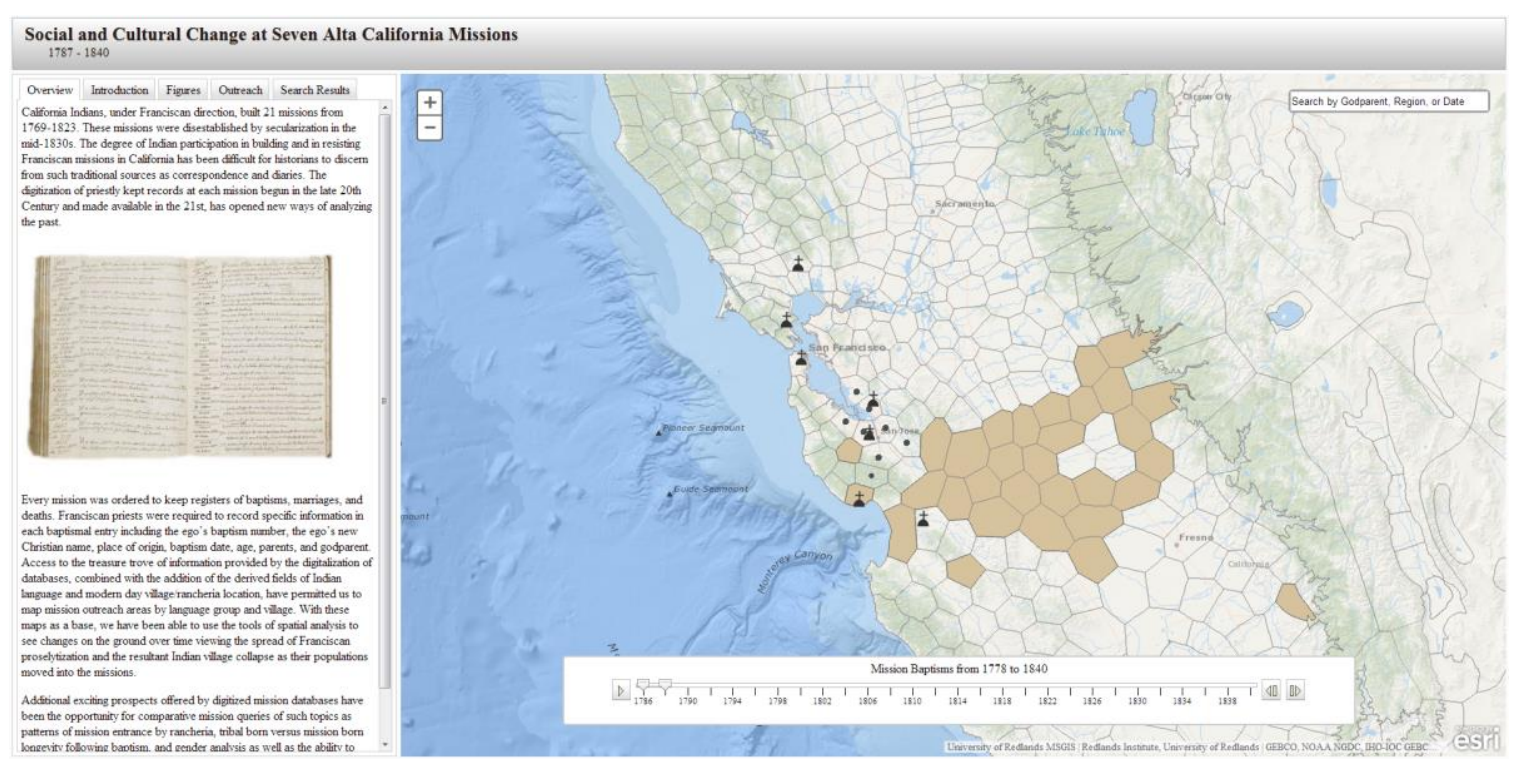

Figure 5.11 Web Application At Open

Each of the five tabs changes hue on mouse over to indicate that each is interactive and may be selected. The content of the "Introduction" and "Figures" tabs introduces the user to the functionality of the site and gives context to the dynamic interactions within the site. The "Outreach" tab houses standardized checkboxes indicating that each outreach may be selected to show on the map or unselected to remove them from the map. The final tab, "Search Results," was labeled similarly to text within the search box which reads, "Search by Godparent, Region, or Date," indicating that the two function together.

If the user wishes to search for a specific individual they are given the option to search one of three fields; Godparent Name, Region or Date of Baptism. These parameters are briefly mentioned in the introduction section for those who may not be familiar with the data used in this application; however further detail is not given as this site is not intended as an introduction to the mission system. After the user enters a search parameter, pressing the "Enter" key initiates the search. If results are available, points representing individuals are displayed on the map. Simultaneously, the table held within "Search Results" tab is populated with relevant information concerning baptisms that met the parameters of the search or query. Figure 5.12 shows the search process and results of searching for the godparent Anacleta. The results of this search show that Anacleta baptized 436 individuals from 29 rancherias and at Mission San Jose from 1813-1833. If the user clicks once within the text box, all text and points on the map are removed, but the tabular results remain. 


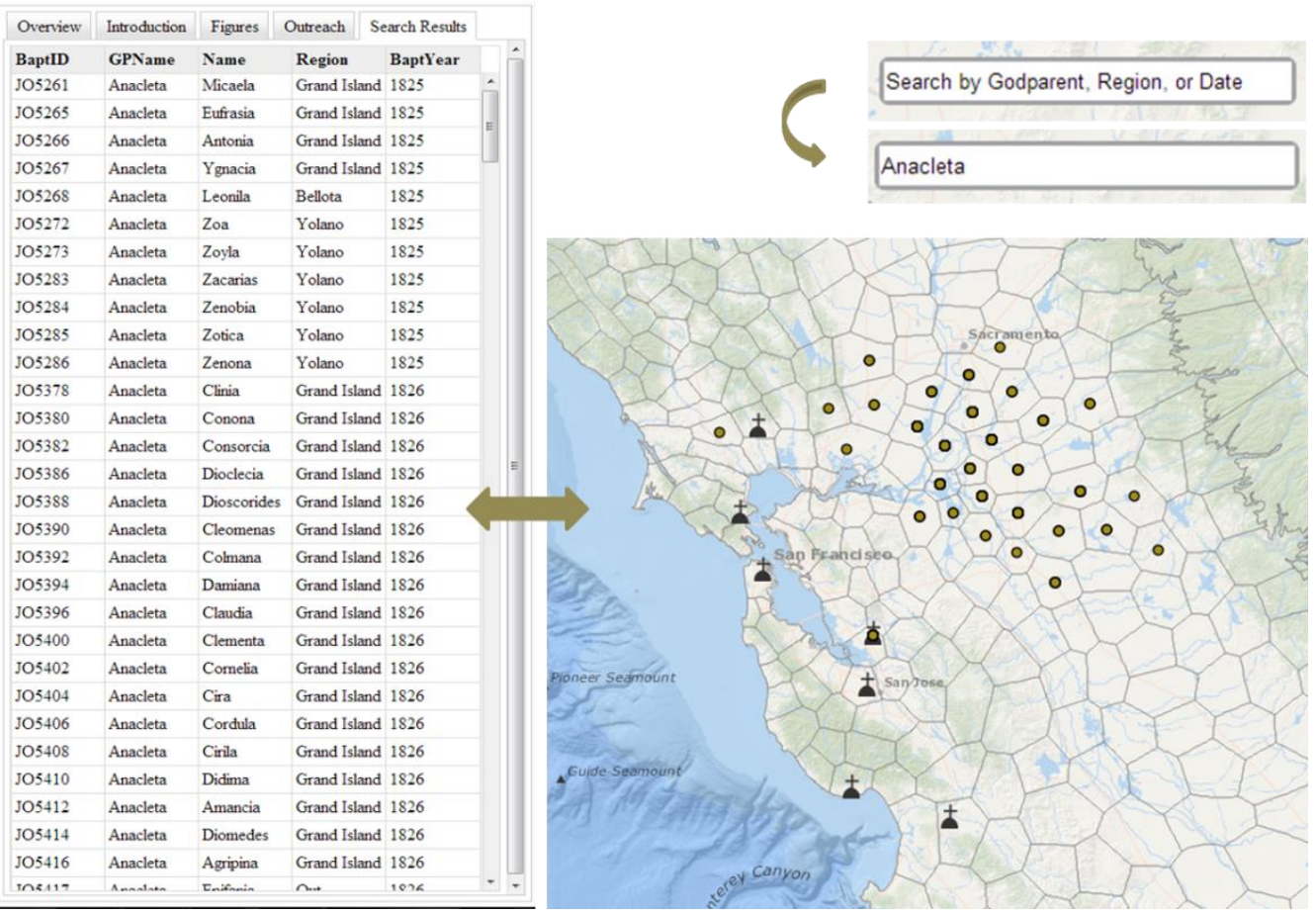

Figure 5.12 Search Use Case

On load, the user will also notice the time slider at the bottom of the page. Points representing individuals associated with the timeline appear in grey on the map. The time slider has two functionalities: the user is able to set a range of years of interest and/or select the play button to show an animation of baptisms over time reflecting the time range previously selected. Figure 5.13 shows baptisms from 1788 to 1794 (top) and baptisms from 1834 to 1830 (bottom), which show the shifting influence of the mission system from west to east. An extra time designation of 1786 (one year before the time range of this study) was chosen so that the user may drag both range tabs to rest at the beginning of the slider range in order to clear the map of point representations. 

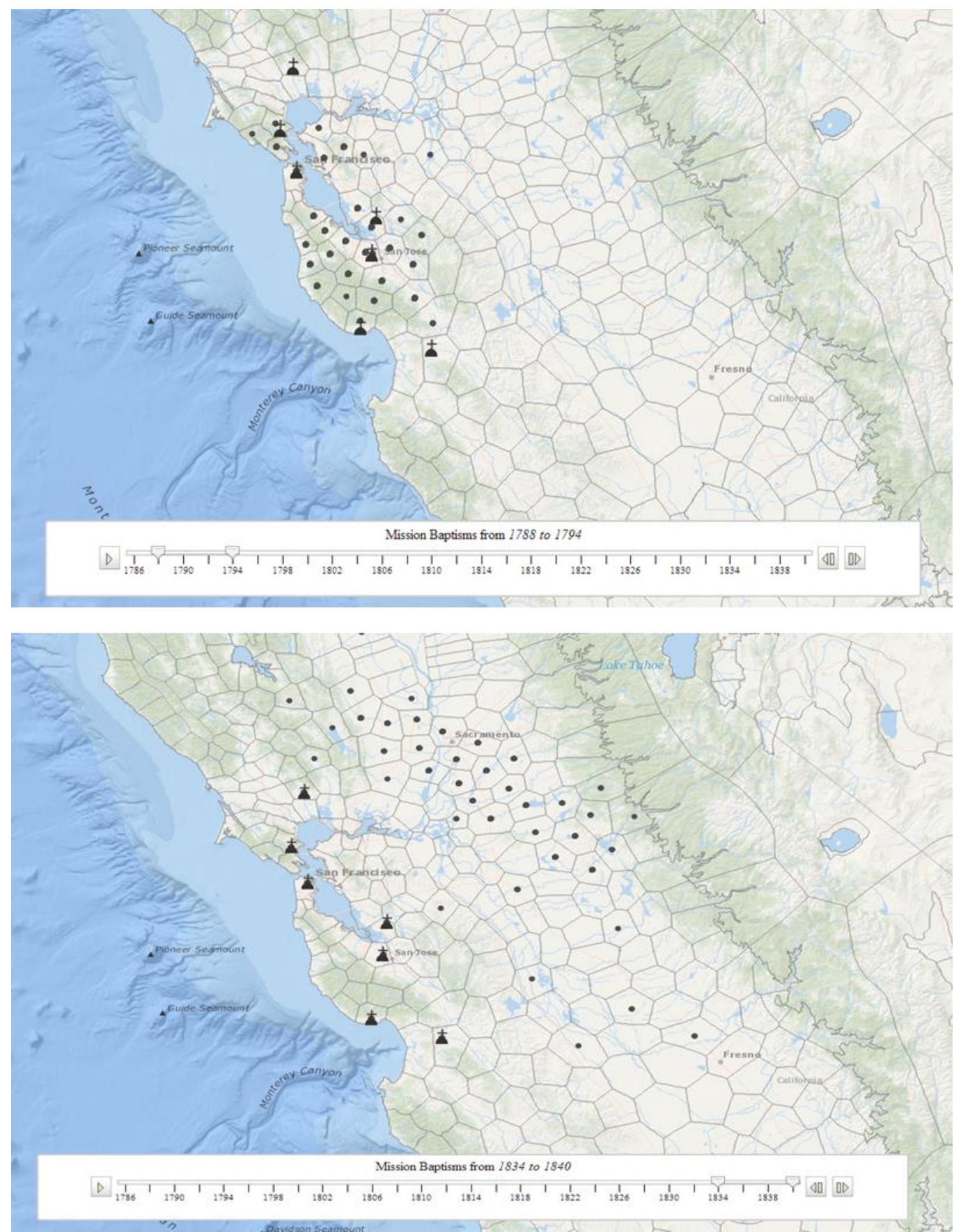

Figure 5.13 Shifting Influences of Missions Over Time

Finally, when missions are selected, a popup window giving more information about each mission appears. This is intended to be intuitive for an audience familiar with web capabilities, but is also briefly mentioned in the "Introduction" tab. Figure 5.14 displays that $27.19 \%$ of individuals baptized at Mission Santa Clara de Asis were of mission origin, and that $46.52 \%$ of all baptized individuals were male. 

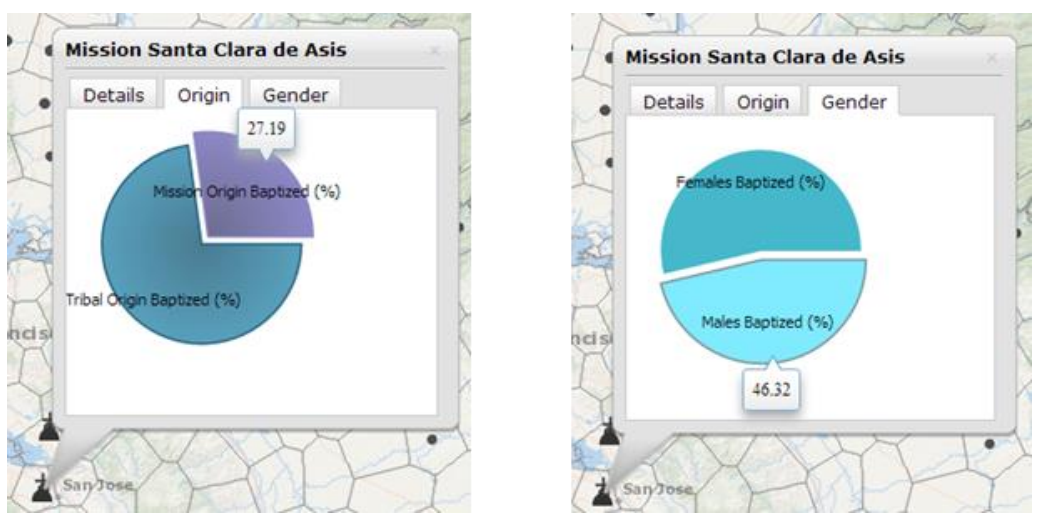

Figure 5.14 Popup Window Results

It was intended that the user of this web application gain further information about the mission system in the San Francisco Bay Area in an approachable manner, which conforms to the current UX trends in web development. A simplistic, easily navigated UI lends itself to a wide variety of uses. While geographic web applications are growing in popularity, even API's lack design elements comparable to the leading websites. This fact will limit the user experience to the confines of the two dimensional map until technology progresses further.

\subsection{Conclusion}

This chapter discussed the methodology behind implementation of the web application. It detailed the interface design elements and functionality incorporated into the application and a use case was provided to guide the user through the intricacies of the website. Chapter 6 will further investigate patterns within mission and tribal populations with the use of statistical analysis methods. Chapter 7 will conclude this thesis. 


\section{Chapter 6 - Results and Analysis}

The main objective of this project was to gain further insight into impact of Spanish colonial missions on historic indigenous communities. Early on, Mission San Jose was defined as the study area locus. To gain a better understanding of the population through statistical analysis, six additional missions were added to the study area; Santa Clara de Asis, Santa Cruz, San Juan Bautista, San Francisco de Asis (Mission Dolores), San Francisco Solano, and San Rafel Arcangel. These additions were decided by the client based on proximity of missions to one another and relationship with the Presidio of San Francisco. Individual records represent baptisms that took place from 1778 through 1840, which were defined by the client as the institution of the first reliable mission records and decline of the mission system.

\subsection{Statistical Analysis Methods}

In as much as the web application interface allows users to interact with mission data, statistical analysis enables the client to explore the depth of the mission geodatabase. Both descriptive and inferential statistics provide insight into how tribal individuals were impacted by the implementation of colonial missions.

\subsubsection{Descriptive Statistical Analysis}

Descriptive statistical analysis of mission data revolved around comparing individuals of different origins within outreach areas of different missions. Attributes were copied from the Individuals ArcGIS feature class and uploaded into SPSS. Then the Frequencies tool was applied to the Origin and Gender fields. The results of this analysis provide a general idea of how baptized populations were distributed between mission and tribal origin, and how those categories were distributed among males and females. To investigate individuals' longevity, an important indicator for the impact of the mission system on indigenous populations, the Year Lived field was added. Year Lived represents the years an individual lived after baptism according to the original BAPTYEAR and DTHYEAR fields. This field was further divided by origin and gender to compare how these subgroups of individuals varied in years lived after baptism.

\subsubsection{Inferential Statistical Analysis}

Inferential statistical analysis methods were employed to gain further insight into the longevity of individuals after baptism. As discussed in Chapter 4, six classifications were decided upon by the client according to a range of time lived after baptism. Each individual was assigned a number that reflected this classification. One way analysis of variance (ANOVA) testing was then performed on both tribal born or mission born populations by each mission. This process was implemented with IBM SPSS software using the workflow outlined in Figure 6.1. 


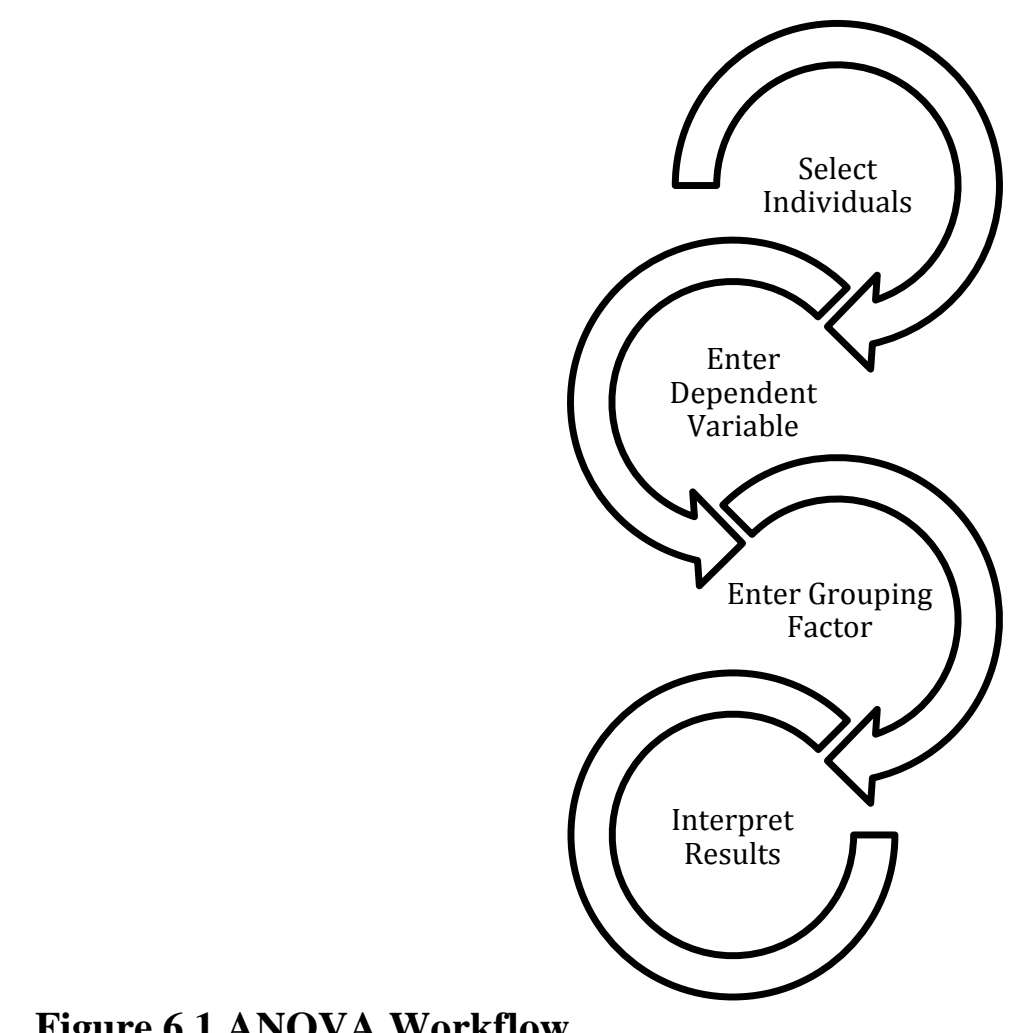

Figure 6.1 ANOVA Workflow

In this scenario, the dependent variable was the YearLived attribute, representing years lived after baptism. Individuals were grouped by the AgeBaptClass classification attribute. Interpretations and enumeration of these results are provided in Section 6.4.

While the ANOVA testing on year lived after baptism by six different age classifications gave a clear understanding of tribal individuals longevity rates, it did not substantiate mission population. Consultation with the client revealed that this is largely because individuals born at missions would have been baptized at birth, thus skewing the understanding of results for comparison. To gain a better understanding of what was happening within mission born population and to add additional context to the results found for individual populations, independent samples $t$ testing was run on YearLived, grouped by gender (Figure 6.2). This process was implemented to test the hypothesis that females lived significantly longer than males in both mission and tribal born populations. 


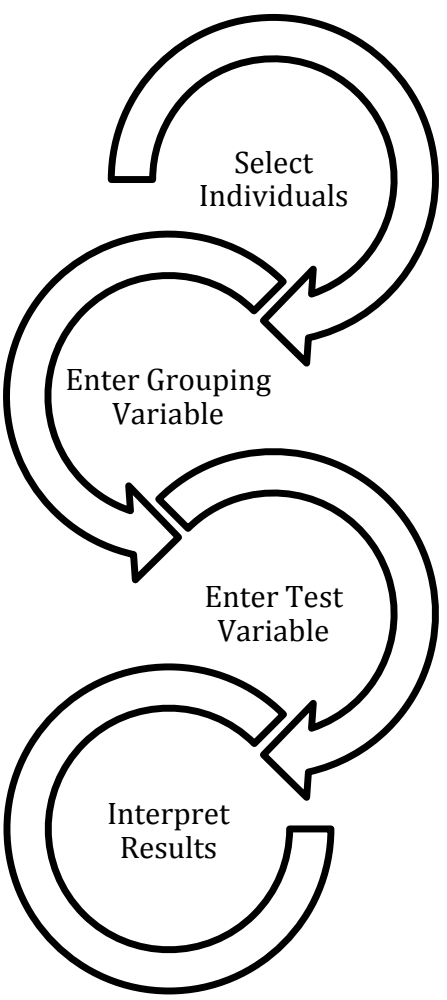

Figure 6.2 Independent Samples $t$ Test Workflow

This test was repeated for individuals who were either mission born or tribal born in each individual mission. The grouping variable was defined as Gender while the test variable was defined as YearLived. The testing results will be presented in Section 6.2.

\subsection{Mission Population Overview}

All seven missions were responsible for the baptism of females and males whose origin was either within the mission itself or from a specific village, also referred to as ranchería. Individuals who were baptized from outside of the mission were considered in this study to be affiliated with tribal origin if a ranchería was indicated. Table 6-1 summarizes the population of each mission.

Table 6-1. Mission Population Summary

\begin{tabular}{lllc}
\hline Mission & Origin & Gender & Number of Individuals \\
\hline Santa Clara de Asis & Mission & Male & 792 \\
& & Female & 824 \\
& & Total & 1616 \\
& \multirow{2}{*}{ Tribal } & Male & 1961 \\
& & Female & 2367 \\
& Total & Male & 4328 \\
& & Female & 2753 \\
& & Total & 3191 \\
& & & 5944 \\
\hline
\end{tabular}




\begin{tabular}{|c|c|c|c|}
\hline \multirow[t]{9}{*}{ Santa Cruz } & \multirow[t]{3}{*}{ Mission } & Male & 162 \\
\hline & & Female & 162 \\
\hline & & Total & 324 \\
\hline & \multirow[t]{3}{*}{ Tribal } & Male & 284 \\
\hline & & Female & 408 \\
\hline & & Total & 692 \\
\hline & \multirow[t]{3}{*}{ Total } & Male & 446 \\
\hline & & Female & 570 \\
\hline & & Total & 1016 \\
\hline \multirow[t]{9}{*}{ San Francisco de Asis } & \multirow[t]{3}{*}{ Mission } & Male & 530 \\
\hline & & Female & 489 \\
\hline & & Total & 1019 \\
\hline & \multirow[t]{3}{*}{ Tribal } & Male & 1462 \\
\hline & & Female & 2031 \\
\hline & & Total & 3493 \\
\hline & \multirow[t]{3}{*}{ Total } & Male & 1992 \\
\hline & & Female & 2520 \\
\hline & & Total & 4512 \\
\hline \multirow[t]{9}{*}{ San Francisco Solano } & \multirow[t]{3}{*}{ Mission } & Male & 24 \\
\hline & & Female & 20 \\
\hline & & Total & 44 \\
\hline & \multirow[t]{3}{*}{ Tribal } & Male & 19 \\
\hline & & Female & 26 \\
\hline & & Total & 45 \\
\hline & \multirow[t]{3}{*}{ Total } & Male & 43 \\
\hline & & Female & 46 \\
\hline & & Total & 89 \\
\hline \multirow[t]{9}{*}{ San Juan Bautista } & \multirow[t]{3}{*}{ Mission } & Male & 513 \\
\hline & & Female & 489 \\
\hline & & Total & 1002 \\
\hline & \multirow[t]{3}{*}{ Tribal } & Male & 458 \\
\hline & & Female & 742 \\
\hline & & Total & 1200 \\
\hline & \multirow[t]{3}{*}{ Total } & Male & 971 \\
\hline & & Female & 1231 \\
\hline & & Total & 2202 \\
\hline \multirow[t]{9}{*}{ San Jose } & \multirow[t]{3}{*}{ Mission } & Male & 664 \\
\hline & & Female & 689 \\
\hline & & Total & 1353 \\
\hline & \multirow[t]{3}{*}{ Tribal } & Male & 2201 \\
\hline & & Female & 2947 \\
\hline & & Total & 5148 \\
\hline & Total & Male & 2865 \\
\hline & & Female & 3636 \\
\hline & & Total & 6501 \\
\hline San Rafael Arcangel & Mission & Male & 45 \\
\hline & & Female & 67 \\
\hline & & Total & 112 \\
\hline & Tribal & Male & 27 \\
\hline & & Female & 67 \\
\hline & & Total & 94 \\
\hline & Total & Male & 72 \\
\hline & & Female & 134 \\
\hline & & Total & 206 \\
\hline Total & Mission & Male & 2730 \\
\hline & & Female & 2740 \\
\hline & & Total & 5470 \\
\hline
\end{tabular}




\begin{tabular}{clc} 
Tribal & Male & 6412 \\
& Female & 8588 \\
\multirow{3}{*}{ Total } & Total & 15000 \\
& Male & 9142 \\
& Female & 11328 \\
& Total & 20470 \\
\hline
\end{tabular}

In total, 20470 individuals had dates of birth, baptism and death necessary for analysis. Of those 20470 , only 27 percent or 5470 individuals were considered to be of mission origin and were evenly split between males and females. The vast majority of individuals were of tribal origin, with females representing slightly more than half (57 percent) of the population. These results conform to the widely accepted understanding that missions themselves contained very small populations, as they were intended primarily as Spanish religious outposts as opposed to large communities.

As the impact of Spanish colonial baptism on mission and tribal populations was the main focus of this study, longevity was measured from date of baptism. In order to understand the differences in baptism between tribal born and mission born populations, percentages of individuals in each of the six categories based on age at baptism were calculated, as shown in Table 6-3. Mission born populations were almost all baptized close to birth. This suggests that baptism occurred within six months of birth for individuals born at each mission. While the baptismal age of tribal born individuals varied significantly, the majority of these individuals were baptized after the age of 16 . This finding reflects the mass baptism effort of missions on an already thriving population. Mission born individuals were largely baptized soon after birth.

Table 6-2. Percentage of Ages at Baptism of Mission and Tribal Origin Individuals

\begin{tabular}{|c|c|c|c|c|}
\hline Mission & Origin & Age at Baptism & Number of Individuals & Percentage \\
\hline \multirow[t]{13}{*}{ Santa Clara de Asis } & \multirow[t]{6}{*}{ Mission } & $0-6$ Months & 1559 & 96.50 \\
\hline & & 6 Months - 1 Year & 3 & 0.20 \\
\hline & & 1 - 5 Years & 3 & 0.20 \\
\hline & & $11-15$ Years & 2 & 0.10 \\
\hline & & $16+$ Years & 49 & 3.00 \\
\hline & & Total & 1616 & 100.00 \\
\hline & \multirow[t]{7}{*}{ Tribal } & $0-6$ Months & 453 & 10.47 \\
\hline & & 6 Months - 1 Year & 114 & 2.63 \\
\hline & & 1 - 5 Years & 574 & 13.26 \\
\hline & & $6-10$ Years & 496 & 11.46 \\
\hline & & $11-15$ Years & 317 & 7.32 \\
\hline & & $16+$ Years & 2374 & 54.85 \\
\hline & & Total & 4328 & 100.00 \\
\hline \multirow[t]{3}{*}{ Santa Cruz } & \multirow[t]{3}{*}{ Mission } & $0-6$ Months & 322 & 0.99 \\
\hline & & $1-5$ Years & 2 & 0.01 \\
\hline & & Total & 324 & 100.00 \\
\hline
\end{tabular}




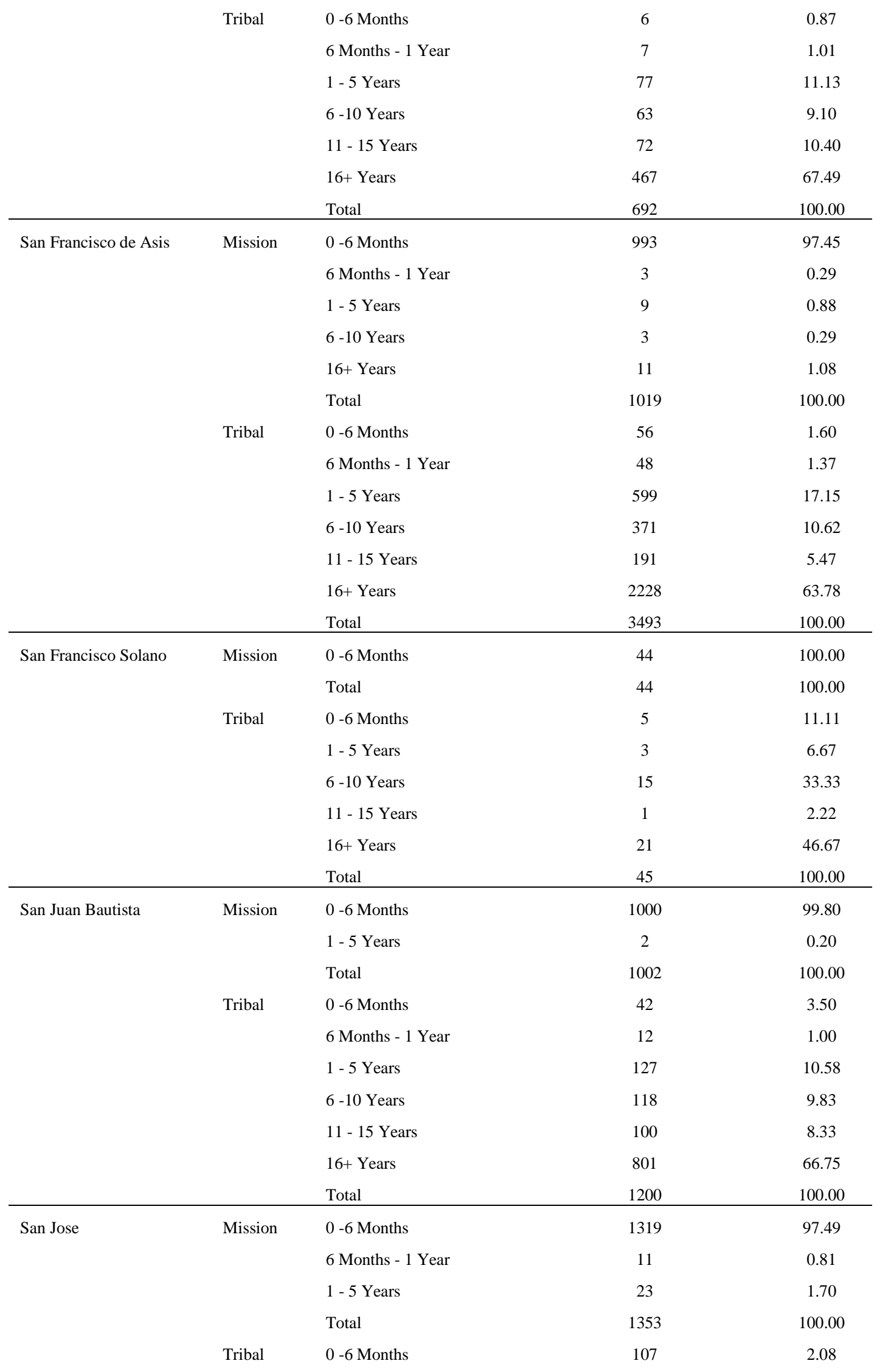




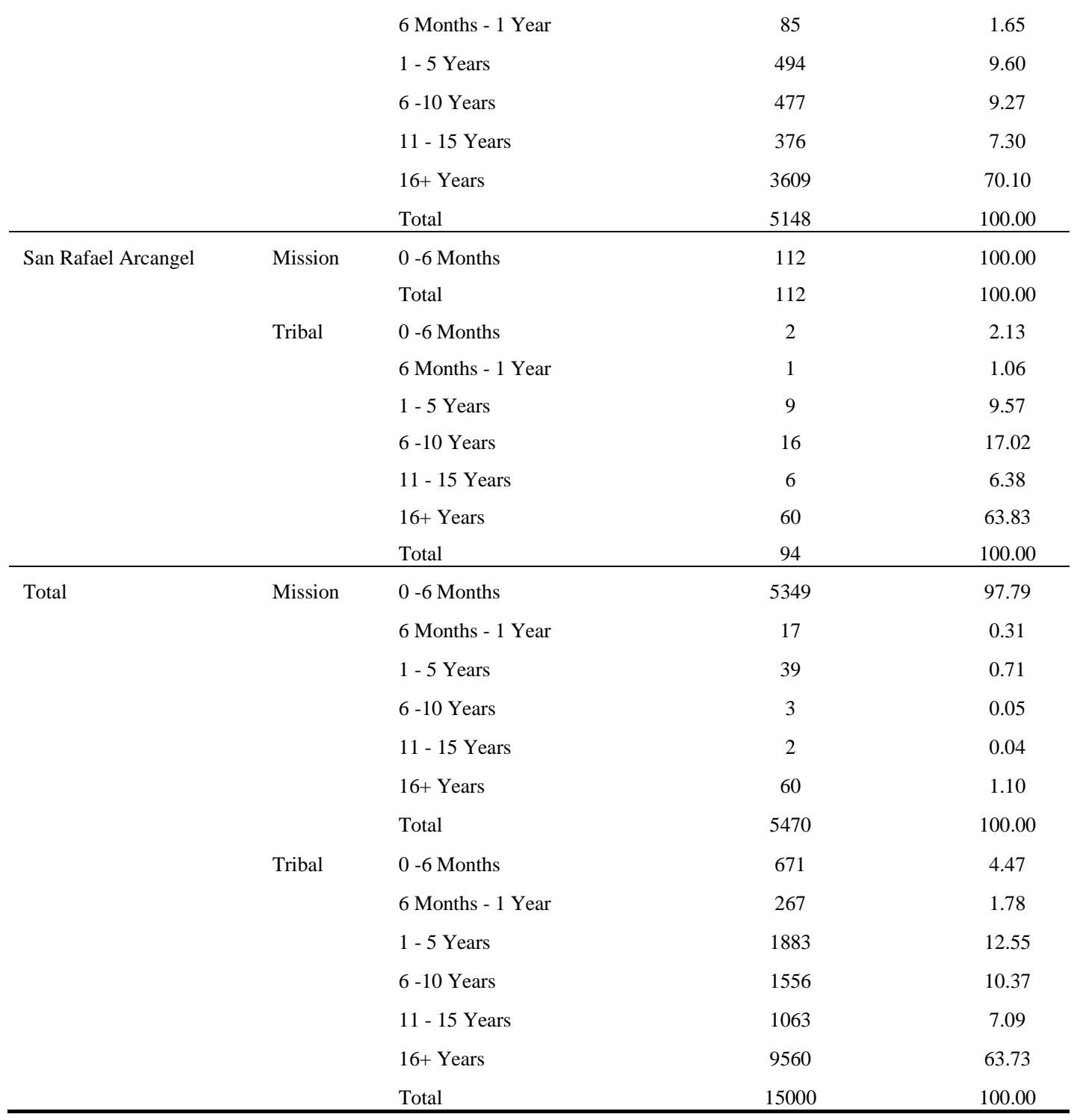

Overall, male and female mission born individuals both lived an average of three years after baptism. This is in contrast to the large dichotomy between male and female longevity in tribal born individuals. While there were more tribal born females baptized at each of the seven missions, males lived significantly longer on average than their female counterparts at every mission except for San Francisco Solano. Table 6-2 details the $t$ test results of years lived after baptism by gender for the mission born and tribal born individuals in each of the seven missions. 
Table 6-3. Longevity of Individuals After Baptism by Gender and Origin 1787-1840

\begin{tabular}{|c|c|c|c|c|c|}
\hline Mission & Origin & Gender & Number of Individuals & Longevity & \\
\hline \multirow[t]{4}{*}{ Santa Clara de Asis } & Mission & Male & 792 & 3.75 & \\
\hline & & Female & 824 & 4.01 & \\
\hline & Tribal & Male & 1961 & 11.02 & $* *$ \\
\hline & & Female & 2367 & 7.43 & $* *$ \\
\hline \multirow[t]{4}{*}{ Santa Cruz } & Mission & Male & 162 & 1.8 & $*$ \\
\hline & & Female & 162 & 2.96 & $*$ \\
\hline & Tribal & Male & 284 & 9.84 & $* *$ \\
\hline & & Female & 408 & 6.7 & $* *$ \\
\hline \multirow[t]{4}{*}{ San Francisco de Asis } & Mission & Male & 530 & 1.78 & \\
\hline & & Female & 498 & 1.97 & \\
\hline & Tribal & Male & 1462 & 7.67 & $* *$ \\
\hline & & Female & 2031 & 5.1 & $* *$ \\
\hline \multirow[t]{4}{*}{ San Francisco Solano } & Mission & Male & 24 & 1.21 & \\
\hline & & Female & 20 & 1.45 & \\
\hline & Tribal & Male & 19 & 1.89 & \\
\hline & & Female & 26 & 2.85 & \\
\hline \multirow[t]{4}{*}{ San Juan Bautista } & Mission & Male & 513 & 2.47 & $* *$ \\
\hline & & Female & 489 & 3.44 & $* *$ \\
\hline & Tribal & Male & 458 & 9.12 & $* *$ \\
\hline & & Female & 742 & 7.19 & $* *$ \\
\hline \multirow[t]{4}{*}{ San Jose } & Mission & Male & 664 & 2.14 & $*$ \\
\hline & & Female & 689 & 2.54 & $*$ \\
\hline & Tribal & Male & 2201 & 8.55 & $* *$ \\
\hline & & Female & 2947 & 5.81 & $* *$ \\
\hline \multirow[t]{4}{*}{ San Rafel Arcangel } & Mission & Male & 45 & 0.82 & \\
\hline & & Female & 67 & 1.06 & \\
\hline & Tribal & Male & 27 & 5.48 & $*$ \\
\hline & & Female & 67 & 4.43 & $*$ \\
\hline
\end{tabular}

Note: $* *: \mathrm{p}<.001 ; *: \mathrm{p}<05$

\subsection{Mission Outreach}

Each mission was associated with a defined outreach area. The outreach area of each mission consists of all rancherias from which all of the individuals who were baptized in this mission were associated as discussed in Chapter 4. This outreach area served the dual purpose of representing the range of impact of a single mission while defining smaller areas of study to analyze longevity by origin within a single mission.

Geographic representation of mission outreaches show that these outreach areas often overlap. Figure 6.3 shows an example of overlap between Mission San Jose and 
Mission Santa Clara de Asis outreaches. The only mission whose outreach is not overlapped more than approximately 50 percent by other mission outreaches is San Francisco Solano. This could be attributed to Solano being the northernmost mission (thus furthest away from the Presidio) or to a later migration event which led to individuals relocating to northern missions after 1817 (Milliken, 2008). In most cases, the outreaches of the missions that are nearer to each other overlap significantly more than those farther away. Larger outreaches such as those representing Missions San Jose and Santa Clara de Asis overlap with up to four other surrounding outreaches.

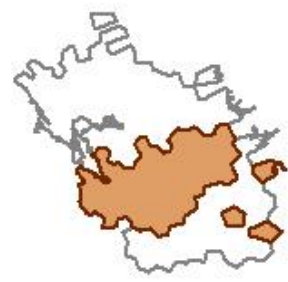

Santa Clara de Asis

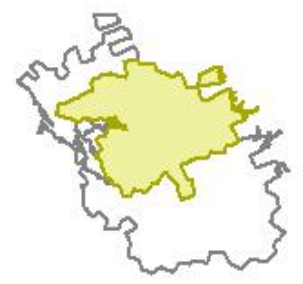

San Jose

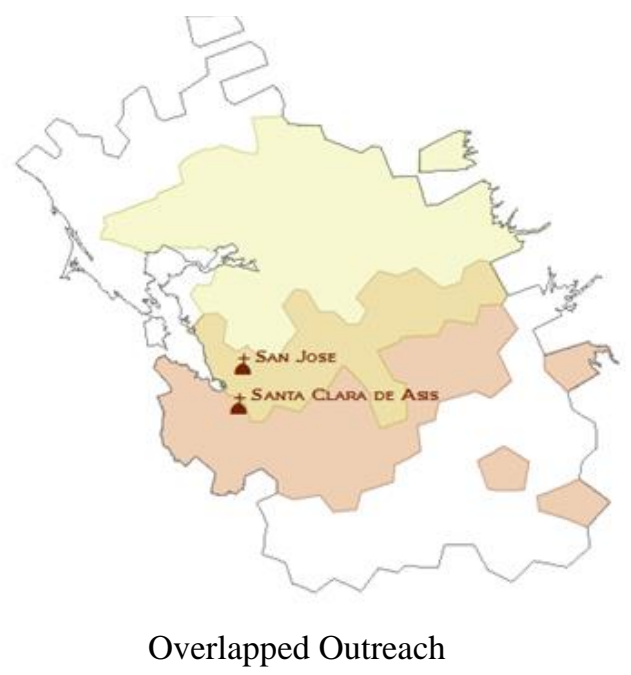

Figure 6.3 Missions Santa Clara de Asis and San Jose Outreach Overlap

The implications of outreach overlap may tell more about the sphere of influence of each mission than suggest a direct association between mission outreaches. A shifting sphere of influence is indicated temporally when the mean and median years of baptism of mission outreaches are compared. For example, of the two largest outreach areas, Mission Santa Clara de Asis has a mean year of baptism of 1804 and median year of baptism of 1813 while Mission San Jose has a mean baptism year of 1817 and median year of baptism of 1818.5. The difference in mean year of baptism indicates that Mission Santa Clara had influence thirteen years before Mission San Jose. Median year of baptism supports the hypothesis that Santa Clara had more influence earlier on than Mission San Jose. Meanwhile, very little overlap is observed when two missions have a mean 
baptismal year less than five years apart, such as in the case of Santa Clara and San Francisco de Asis, thus suggesting that missions that have overlapping outreaches were dominant at different time periods. These time periods of greater influence trend northward, ending with the two northernmost missions, Rafel Arcangel and Solano, having the latest mean year of baptism at 1827 and 1835 and median year of baptism at 1831.5 and 1835.5 respectively. This finding supports Milliken's assertion that a later northern migration took place and hints at a changing interaction between missions and tribal communities. Percentages of overlap per mission outreach along with mean baptism year are shown in Table 6-4.

Table 6-4. Outreach Overlap by Mission

\begin{tabular}{|c|c|c|c|c|c|}
\hline Mission & $\begin{array}{l}\text { Total } \\
\text { Population }\end{array}$ & $\begin{array}{l}\text { Mean Bap } \\
\text { Year }\end{array}$ & $\begin{array}{l}\text { Median Bap } \\
\text { Year }\end{array}$ & Overlapping Outreach & $\begin{array}{l}\text { Percentage } \\
\text { Overlap }\end{array}$ \\
\hline \multirow[t]{4}{*}{ Santa Clara de Asis } & 5944 & 1804 & 1813 & Santa Cruz & $12 \%$ \\
\hline & & & & San Francisco de Asis & $8 \%$ \\
\hline & & & & San Juan Bautista & $6 \%$ \\
\hline & & & & San Jose & $33 \%$ \\
\hline \multirow[t]{4}{*}{$\begin{array}{l}\text { San Francisco de } \\
\text { Asis }\end{array}$} & 4512 & 1806 & 1815.5 & Santa Clara de Asis & $13 \%$ \\
\hline & & & & San Francisco Solano & $2 \%$ \\
\hline & & & & San Rafel Arcangel & $6 \%$ \\
\hline & & & & San Jose & $43 \%$ \\
\hline \multirow[t]{3}{*}{ Santa Cruz } & 1016 & 1813 & 1821 & Santa Clara de Asis & $13 \%$ \\
\hline & & & & San Juan Bautista & $48 \%$ \\
\hline & & & & San Jose & $2 \%$ \\
\hline \multirow[t]{2}{*}{ San Juan Bautista } & 2202 & 1816 & 1816 & Santa Clara de Asis & $6 \%$ \\
\hline & & & & Santa Cruz & $43 \%$ \\
\hline \multirow[t]{4}{*}{ San Jose } & 6501 & 1817 & 1818.5 & Santa Clara de Asis & $27 \%$ \\
\hline & & & & San Francisco Solano & $1 \%$ \\
\hline & & & & San Francisco de Asis & $20 \%$ \\
\hline & & & & San Rafel Arcangel & $2 \%$ \\
\hline \multirow[t]{3}{*}{ San Rafel Arcangel } & 206 & 1827 & 1831.5 & San Francisco Solano & $17 \%$ \\
\hline & & & & San Francisco de Asis & $20 \%$ \\
\hline & & & & San Jose & $15 \%$ \\
\hline \multirow[t]{3}{*}{$\begin{array}{l}\text { San Francisco } \\
\text { Solano }\end{array}$} & 89 & 1835 & 1835.5 & San Francisco de Asis & $4 \%$ \\
\hline & & & & San Jose & $5 \%$ \\
\hline & & & & San Rafel Arcangel & $8 \%$ \\
\hline
\end{tabular}

\subsection{Longevity of Baptized Individuals}

Longevity of both mission born and tribal born individuals was explored by age of baptism delineated by the client, as discussed in Chapter 3. Table 6-5 shows the 
significance of mean longevity of mission and tribal born individuals. It is immediately apparent from these findings that tribal born individuals lived significantly longer after baptism than mission born individuals. However, it is important to take into account a number of factors, such as age of individuals at baptism and sample size.

\section{Table 6-5. Average Years Lived After Baptism by Origin}

\begin{tabular}{|c|c|c|c|c|}
\hline Mission & Origin & $\begin{array}{l}\text { Number of } \\
\text { Individuals }\end{array}$ & Avg Year Lived & \\
\hline \multirow[t]{3}{*}{ Santa Clara de Asis } & Mission & 1616 & 3.88 & $*$ \\
\hline & Tribal & 4328 & 9.06 & $*$ \\
\hline & Total & 5944 & 7.65 & \\
\hline \multirow[t]{3}{*}{ Santa Cruz } & Mission & 324 & 2.38 & $*$ \\
\hline & Tribal & 692 & 7.99 & $*$ \\
\hline & Total & 1016 & 6.20 & \\
\hline \multirow[t]{3}{*}{ San Francisco de Asis } & Mission & 1019 & 1.87 & * \\
\hline & Tribal & 3493 & 6.17 & $*$ \\
\hline & Total & 4512 & 5.20 & \\
\hline \multirow[t]{3}{*}{ San Francisco Solano } & Mission & 44 & 1.32 & \\
\hline & Tribal & 45 & 2.44 & \\
\hline & Total & 89 & 1.89 & \\
\hline \multirow[t]{3}{*}{ San Juan Bautista } & Mission & 1002 & 2.94 & * \\
\hline & Tribal & 1200 & 7.92 & $*$ \\
\hline & Total & 2202 & 5.66 & \\
\hline \multirow[t]{3}{*}{ San Jose } & Mission & 1353 & 2.34 & $*$ \\
\hline & Tribal & 5148 & 6.98 & $*$ \\
\hline & Total & 6501 & 6.02 & \\
\hline \multirow[t]{3}{*}{ San Rafael Arcangel } & Mission & 112 & .96 & $*$ \\
\hline & Tribal & 94 & 4.73 & $*$ \\
\hline & Total & 206 & 2.68 & \\
\hline
\end{tabular}

$*: \mathrm{p}<.001$

Analysis of variance (ANOVA) testing was used to compare the number of years individuals of mission and tribal origin lived after baptism across different age groups. For mission born individuals, ANOVA results indicate insignificant differences across different age groups, which is due to the fact that the majority of baptisms occurring at missions were of infants less than six months old. Findings are significant for tribal born populations at all missions except for San Francisco Solano and San Rafel Arcangel (the two missions with the latest mean baptism years). In concurrence with the $t$ test results on longevity by gender, longevity after baptism significantly varies across different age groups of the tribal born individuals.

Table 6-6 shows the ANOVA results concerning longevity by age of baptism. Generally speaking, longevity after baptism increased when an individual was baptized at an older age. For example, individuals baptized under six months, except for the infants 
from Santa Clara de Asis, did not live for more than three years on average after baptism, while older individuals usually survived for approximately six to nine years after baptism. This trend most likely reflects the resistance of older individuals to disease that was introduced by Spanish colonists, as discussed in Chapter 2.

Table 6-6. Longevity of Individuals After Baptism by Age Baptized 1787-1840

\begin{tabular}{|c|c|c|c|c|c|}
\hline Mission & Origin & Age Baptized & Number of Individuals & Longevity & \\
\hline \multirow[t]{10}{*}{ Santa Clara de Asis } & Mission & Less than 6 months & 1559 & 3.75 & $* *$ \\
\hline & & 6 months + & 57 & 7.61 & $* *$ \\
\hline & & Total & 1616 & 3.88 & \\
\hline & Tribal & Less than 6 months & 453 & 5.56 & $* *$ \\
\hline & & 6 months to 1 year & 114 & 7.9 & $* *$ \\
\hline & & $1-5$ years & 574 & 11.16 & $* *$ \\
\hline & & $6-10$ years & 496 & 10.34 & $* *$ \\
\hline & & $11-15$ years & 317 & 10.1 & $* *$ \\
\hline & & Over 16 years & 2374 & 8.87 & $* *$ \\
\hline & & Total & 4328 & 9.06 & \\
\hline \multirow[t]{8}{*}{ Santa Cruz } & Mission & Less than 6 months & 322 & 2.33 & \\
\hline & & $1-5$ years & 2 & 11 & \\
\hline & & Total & 324 & 5.396 & \\
\hline & Tribal & Less than 5 years & 90 & 9.59 & $* *$ \\
\hline & & $6-10$ years & 63 & 7.97 & $* *$ \\
\hline & & $11-15$ years & 72 & 7.49 & $* *$ \\
\hline & & Over 16 years & 467 & 9.46 & $* *$ \\
\hline & & Total & 692 & 7.99 & \\
\hline \multirow[t]{10}{*}{ San Francisco de Asis } & Mission & Less than 6 months & 993 & 1.88 & \\
\hline & & Over 6 months & 26 & 1.42 & \\
\hline & & Total & 1019 & 1.87 & \\
\hline & Tribal & Less than 6 months & 56 & 2.52 & $* *$ \\
\hline & & 6 months to 1 year & 48 & 4.73 & $* *$ \\
\hline & & $1-5$ years & 599 & 5.99 & $* *$ \\
\hline & & $6-10$ years & 371 & 8.61 & $* *$ \\
\hline & & $11-15$ years & 191 & 8.4 & $* *$ \\
\hline & & Over 16 years & 2228 & 5.75 & $* *$ \\
\hline & & Total & 3493 & 6.17 & \\
\hline \multirow[t]{2}{*}{ San Francisco Solano } & Mission & Less than 6 months & 44 & 1.31 & \\
\hline & & Total & 44 & 1.31 & \\
\hline
\end{tabular}




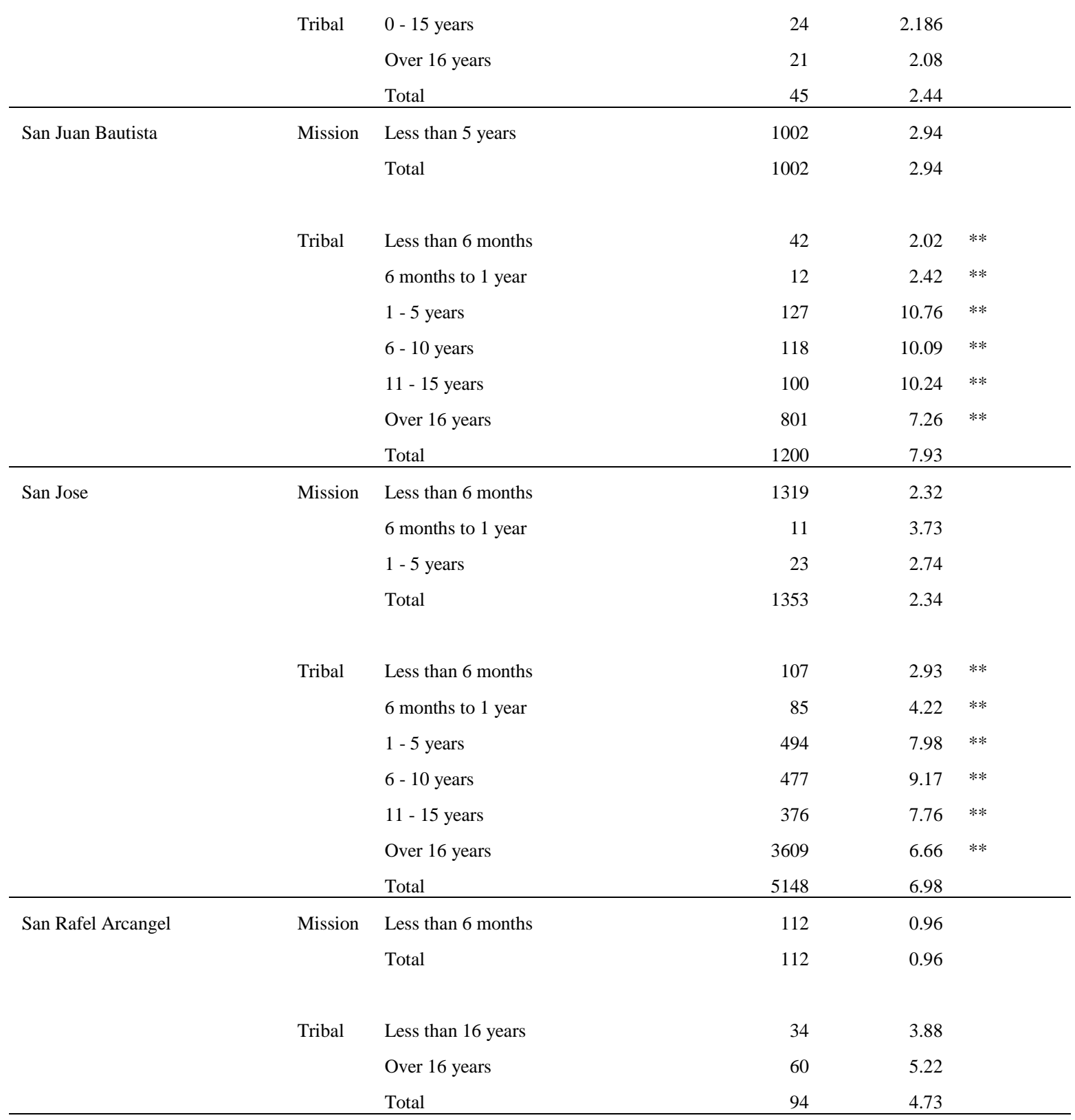

Note: $* * \mathrm{p}<.005$

\subsection{Summary}

This chapter explored the relationships between individuals on spatial and statistical levels. An overview of the study area composition was given, and substantiated further by examining longevity by gender. Longevity was further discussed when expected years lived after baptism between individuals of mission and tribal origin were compared and contrasted. In Chapter 7, recommendations for future research will be made. 


\section{Chapter 7 - Conclusions and Future Work}

During the course of this major individual project, two databases representing related yet disparate data concerning Spanish mission baptismal records were joined. Individuals of Spanish and indigenous heritage were located geographically within rancherías. From this data, points and polygons were effused with new attribute data which broadened the narrative on the influence of mission system implementation on preexisting native lifeways. The relationship between historic indigenous people and Spanish colonialism was investigated with statistical analysis. This analysis led to final decisions about how to spatially represent individuals on the web.

These steps were only possible with the insight given by James and Tish Sandos, shapefiles created by Randall Milliken, and the previous data exploration conducted by the Redlands Institute, which contributed to the general database structure, upon which this work was based.

There is still much work that can be done on this topic. Questions raised about the importance of mission outreaches and the implications of shifting spheres of influence regarding individual missions might be further explored by investigating the temporal and spatial relationships of baptism events. Specifically, a better understanding of mission communities might be supported by finding out more about individuals baptized at contact, enumerating the populations who lived their entire lives under the mission system and those who were baptized during colonial decline whose deaths were never recorded due to the Spanish leaving the area. Statistical regression analysis of these populations would provide further insight into possible impacts of missions on the longevity of indigenous peoples.

Statistical representation of populations combined with horizontal, vertical and temporal spatial analysis provides the opportunity to geographically represent indigenous individuals impacted by the mission system. A georepresentational approach allows for new questions to be asked about the inner workings of the Alta California indigenous population that was not represented by writing until contact with Spanish colonialists. While old perceptions of individuals who lived during the Mission period may be reified by spatial thinking, new theories may also be fostered which enhance our understanding of a much researched but still ethnographically ambiguous time. 



\section{Works Cited}

Collections, S. C. (n.d.). Santa Clara Mission Records. Retrieved from Santa Clara University Digital Collections:

http://content.scu.edu/cdm/singleitem/collection/mission/id/194

Gregory, I. N., \& Ell, P. S. (2007). Historical GIS: Technologies Methodologies and Scholarship. Cambridge, United Kingdom: University Press.

Jackson, R. H. (1983). Disease and Demographic Patterns at Santa Cruz Mission, Alta California. Journal of California and Great Basin Anthropology, 5(1/2), 33-57.

Milliken, R. (2008). Native Americans at Mission San Jose. Banning, CA: Malki-Ballena Press.

Peelo, S. (2009). Baptism among the Salinan Neophytes of Mission San Antionio de Padua: Investigating the Ecological Hypothesis. Ethnohistory, 56(4), 589-624.

Sandos, J. A. (1997). Between Crucifix and Lance: Indian-White Relations in California, 1769-1878. California History, 76(No. 2/3), 196-229.

Skrowronek, R. K. (1998). Sifting the Evidence: Perceptions of Life at the Ohlone (Costoanoan) Missions of Alta California. Ethnohistory, 45(4), 675-708. 



\section{Appendix A. Client Statement (Web Application)}

"California Indians, under Franciscan direction, built 21 missions from 1769-1823. These missions were disestablished by secularization in the mid-1830s. The degree of Indian participation in building and in resisting Franciscan missions in California has been difficult for historians to discern from such traditional sources as correspondence and diaries. The digitization of priestly kept records at each mission begun in the late 20th Century and made available in the 21 st has opened new ways of analyzing the past.

Every mission was ordered to keep registers of baptisms, marriages, and deaths. Franciscan priests were required to record specific information in each baptismal entry including the ego's baptism number, the ego's new Christian name, place of origin, baptism date, age, parents, and godparent. Access to the treasure trove of information provided by the digitalization of databases, combined with the addition of the derived fields of Indian language and modern day village/ranchería location, have permitted us to map mission outreach areas by language group and village. With these maps as a base, we have been able to use the tools of spatial analysis to see changes on the ground over time viewing the spread of Franciscan proselytization and the resultant Indian village collapse as their populations moved into the missions.

Additional exciting prospects offered by digitized mission databases have been the opportunity for comparative mission queries of such topics as patterns of mission entrance by ranchería, tribal born versus mission born longevity following baptism, and gender analysis as well as the ability to track individuals and their connections to other members of the mission community. From this work we are gaining powerful new insights into the dynamics and the tragedy of the California Mission period." 


\section{Appendix B. Web Application Code}

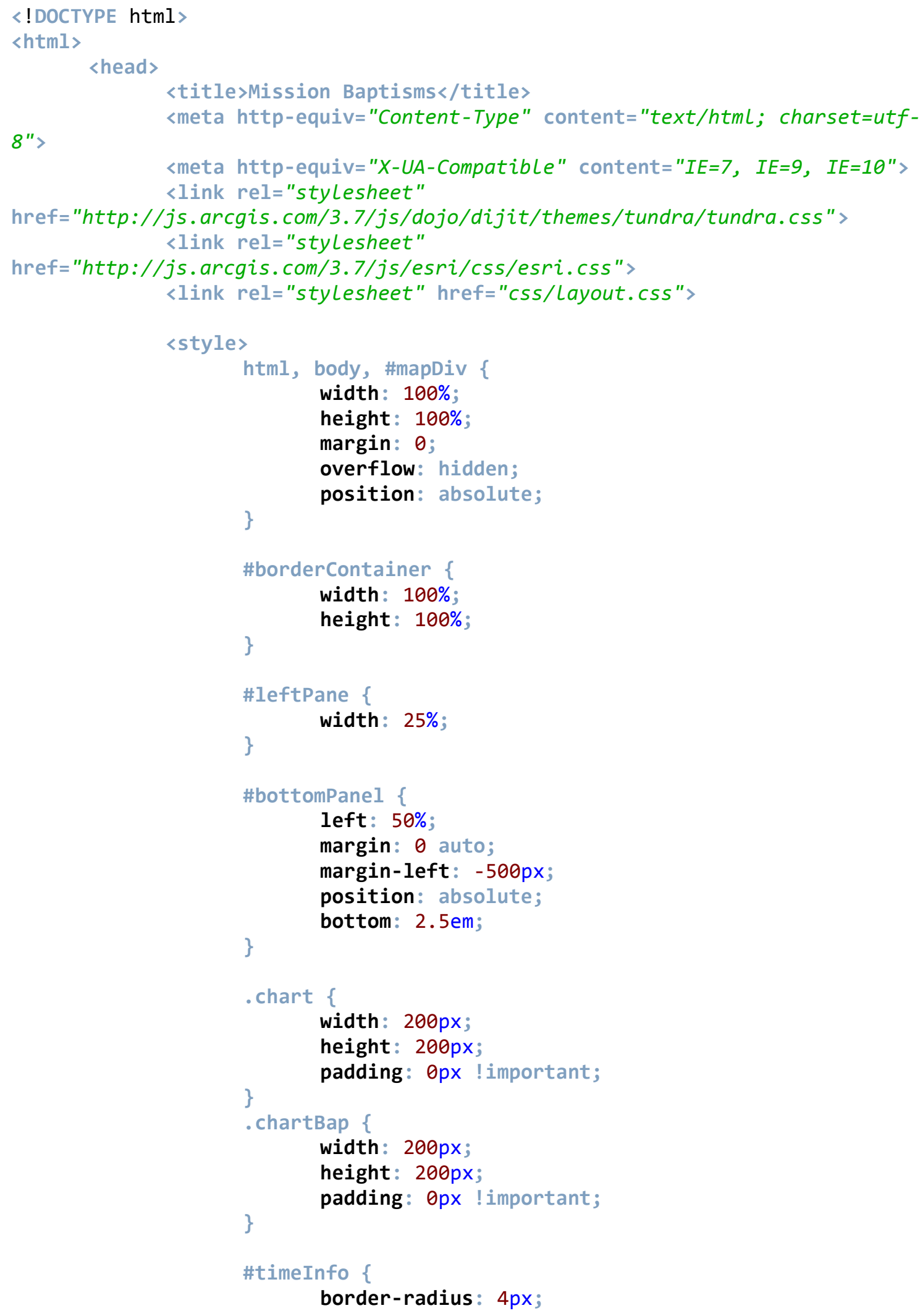




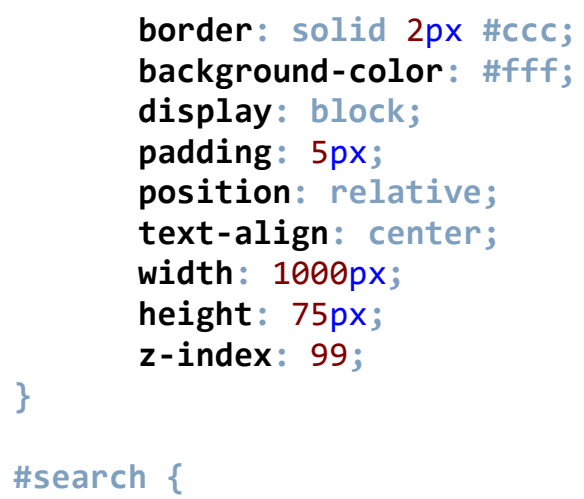




\section{parser.parse();}

\section{function}

//Create Grid to store results of Godparent query

dojo.create("div"));

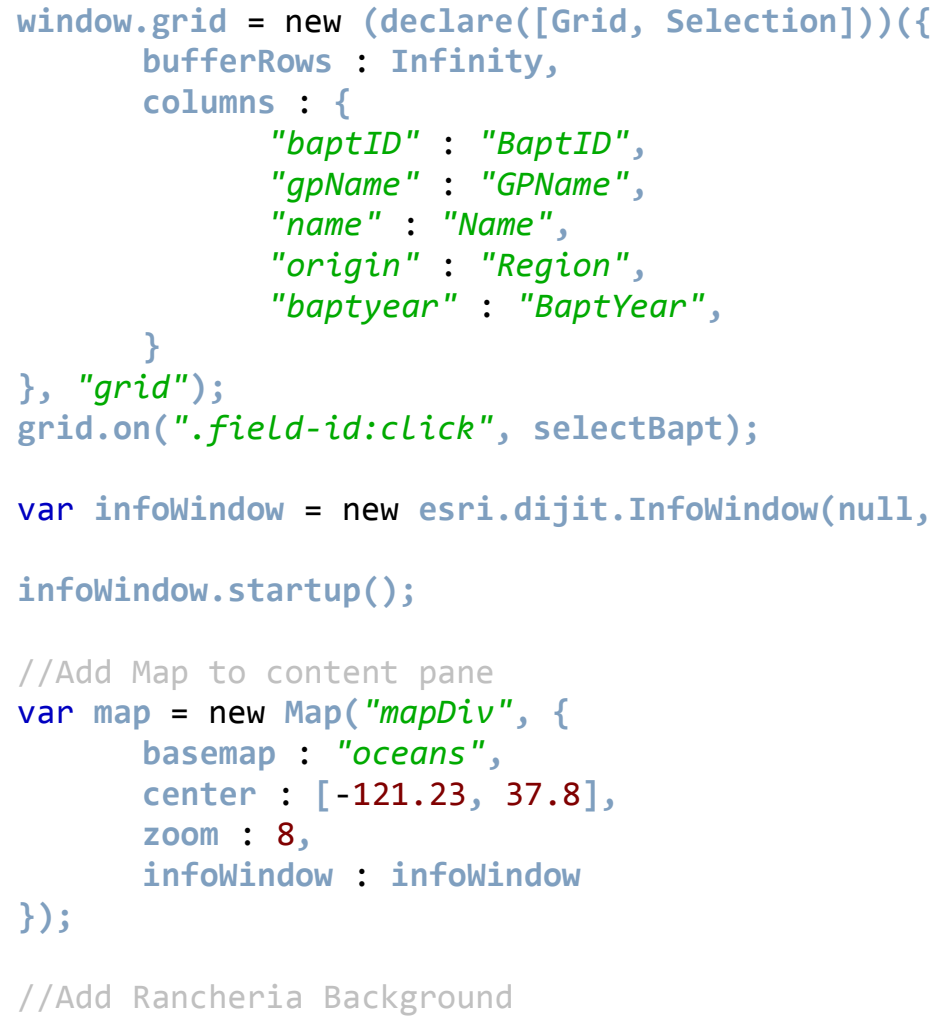


var missionImg $=$ "<img src='http://msgis-

webdev-1.spatial.redlands.edu/MSGIS/katherine_smyth/missionsymbol.png'

alt= 'MissionIcon' >";

missionImg;

dom.byId("missionImg").innerHTML =

var resultImg = "<img src='http://msgis-

webdev-1.spatial.redLands.edu/MSGIS/katherine_smyth/regionResult.jpg'

alt='SearchResult'>";

resultImg;

dom.byId("searchResult").innerHTML =

var outreachImg = "<img src='http://msgis-

webdev-

1.spatial.redlands.edu/MSGIS/katherine_smyth/missionoutreaches/Jooutreach.jpg' alt= 'outreachImage '>";

outreachImg; dom.byId("outreachImg"). innerHTML =

//add static chart images

var firstchart $=$ "<img $s r c=$ 'http://msgis -

webdev-1.spatial.redlands.edu/MSGIS/katherine_smyth/popFigTwo.png'

alt='ChartOne' width='400' height='300' >";

firstChart;

dom.byId("insetThree"). innerHTML =

var secondChart $=$ "<img src='http://msgis -

webdev-1.spatial.redLands.edu/MSGIS/katherine_smyth/popFigone.png'

alt='ChartTwo' width='400' height='300'>";

dom.byId("insetTwo").innerHTML = secondChart;

var popDens = "<img src='http://msgis-webdev-

1.spatial.redlands.edu/MSGIS/katherine_smyth/popDens.png'

alt='PopulationDensity' width='400' height= '452' >";

dom.byId("insetOne").innerHTML = popDens;

//add images for all outreaches

webdev-

var outreach1 = "<img src='http://msgis-

1. spatial.redlands.edu/MSGIS/katherine_smyth/missionOutreaches/CLoutreach.jpg' alt= 'outreach1'>";

dom.byId("outreach1").innerHTML = outreach1;

var outreach2 = "<img $s r c=$ "http://msgis -

webdev-

1.spatial.redlands.edu/MSGIS/katherine_smyth/missionoutreaches/RAoutreach.jpg' alt='outreach2'>";

webdev-

dom.byId("outreach2").innerHTML = outreach2;

var outreach3 = "<img src='http://msgis-

1.spatial.redlands.edu/MSGIS/katherine_smyth/missionOutreaches/JOoutreach.jpg' alt='outreach3'>";

dom.byId("outreach3").innerHTML = outreach3;

var outreach4 = "<img src='http://msgis-

webdev-

1.spatial.redlands.edu/MSGIS/katherine_smyth/missionoutreaches/JBoutreach.jpg' alt='outreach4 '>";

dom.byId("outreach4").innerHTML = outreach4;

webdev-

var outreach5 = "<img src='http://msgis - 
1.spatial.redlands.edu/MSGIS/katherine_smyth/missionoutreaches/FSoutreach.jpg ' alt='outreach5' >";

webdev-

dom.byId("outreach5").innerHTML = outreach5;

var outreach6 = "<img src="http://msgis-

1.spatial.redlands.edu/MSGIS/katherine_smyth/missionoutreaches/FRoutreach.jpg ' alt='outreach6' >"; dom.byId("outreach6").innerHTML = outreach6; var outreach7 = "<img src='http://msgis -

webdev-

1.spatial.redlands.edu/MSGIS/katherine_smyth/missionOutreaches/CRoutreach.jpg' alt='outreach7'>";

dom.byId("outreach7").innerHTML = outreach7;

is pressed

//tells the search box to search when enter

//sometimes the search box requires enter to

be pressed twice, but more importantly, there is no way to clear it or the graphics off of the map

function(evt) \{

on(dom.byId("searchbox"), "keypress",

dom.byId("searchbox").value;

if (evt.keyCode $==13$ ) \{

var qStr $=$

if (qStr.length $>0$ ) \{

\} querySomething(qStr);

evt.preventDefault();

\}

\});

\});

//this function allows the user to clear the search box on click. it also clears results from the grid and map.

on(dom.byId("searchbox"), "click", function(evt) \{ dom.byId("searchbox"),value = ""; map.graphics.clear();

\});

//Use the ImageParameters to set the visible layers

in the map service during ArcGISDynamicMapServiceLayer construction.

var imageParameters $=$ new

esri.layers.ImageParameters();

imageParameters. layerIds $=[6]$;

imageParameters. layeroption =

esri.layers.ImageParameters.LAYER_OPTION_SHOW;

//can also be: LAYER_OPTION_EXCLUDE,

LAYER_OPTION_HIDE, LAYER_OPTION_INCLUDE

layer $=$ new

esri.layers.ArcGISDynamicMapServiceLayer("http://msgis-webdev-

1.spatial.redlands.edu/arcgis/rest/services/katherine_smyth/MissionOutreachInd v/MapServer", \{

"imageParameters" : imageParameters 


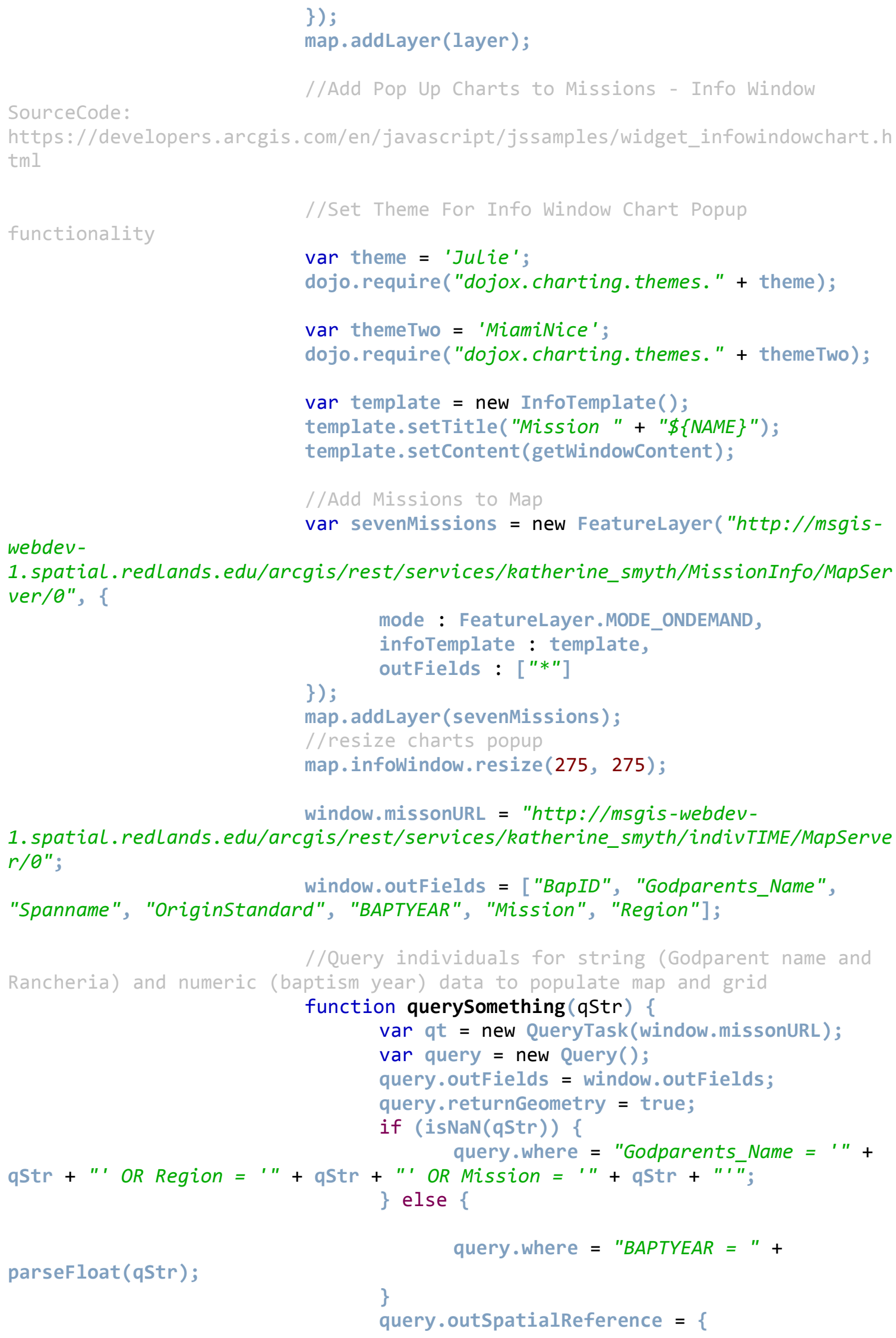




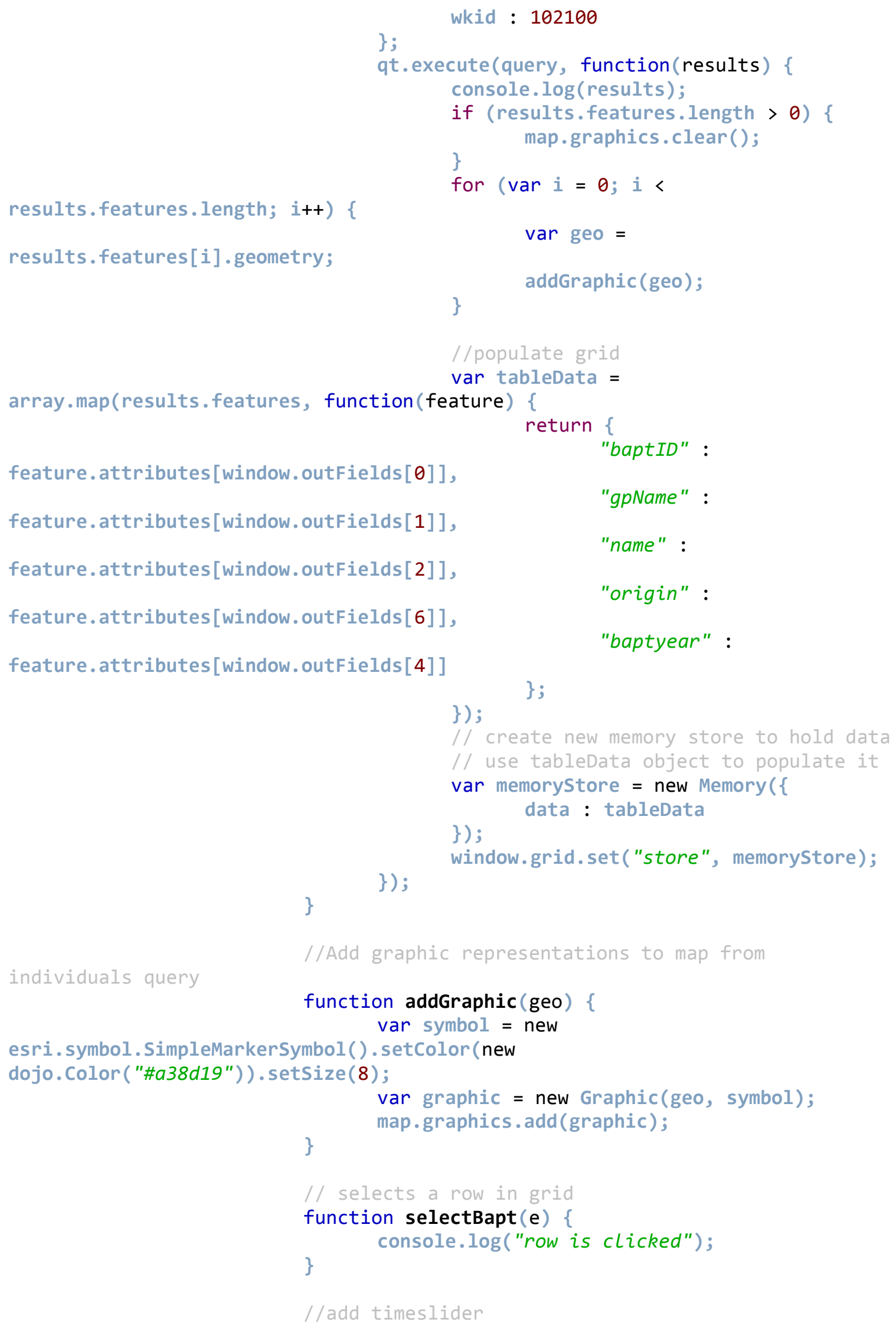


https://developers.arcgis.com/en/javascript/jssamples/widget_infowindowchart.h tml

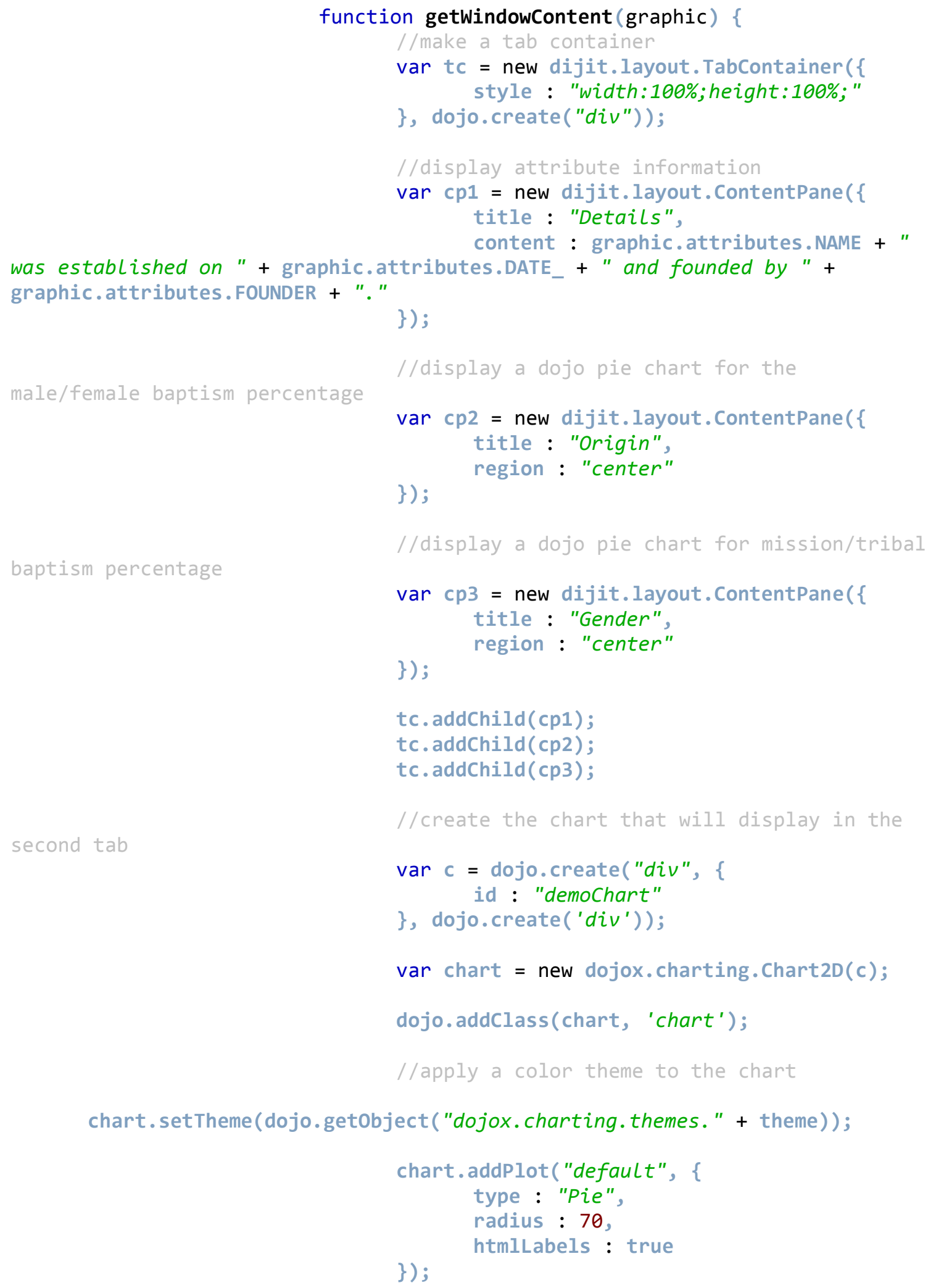




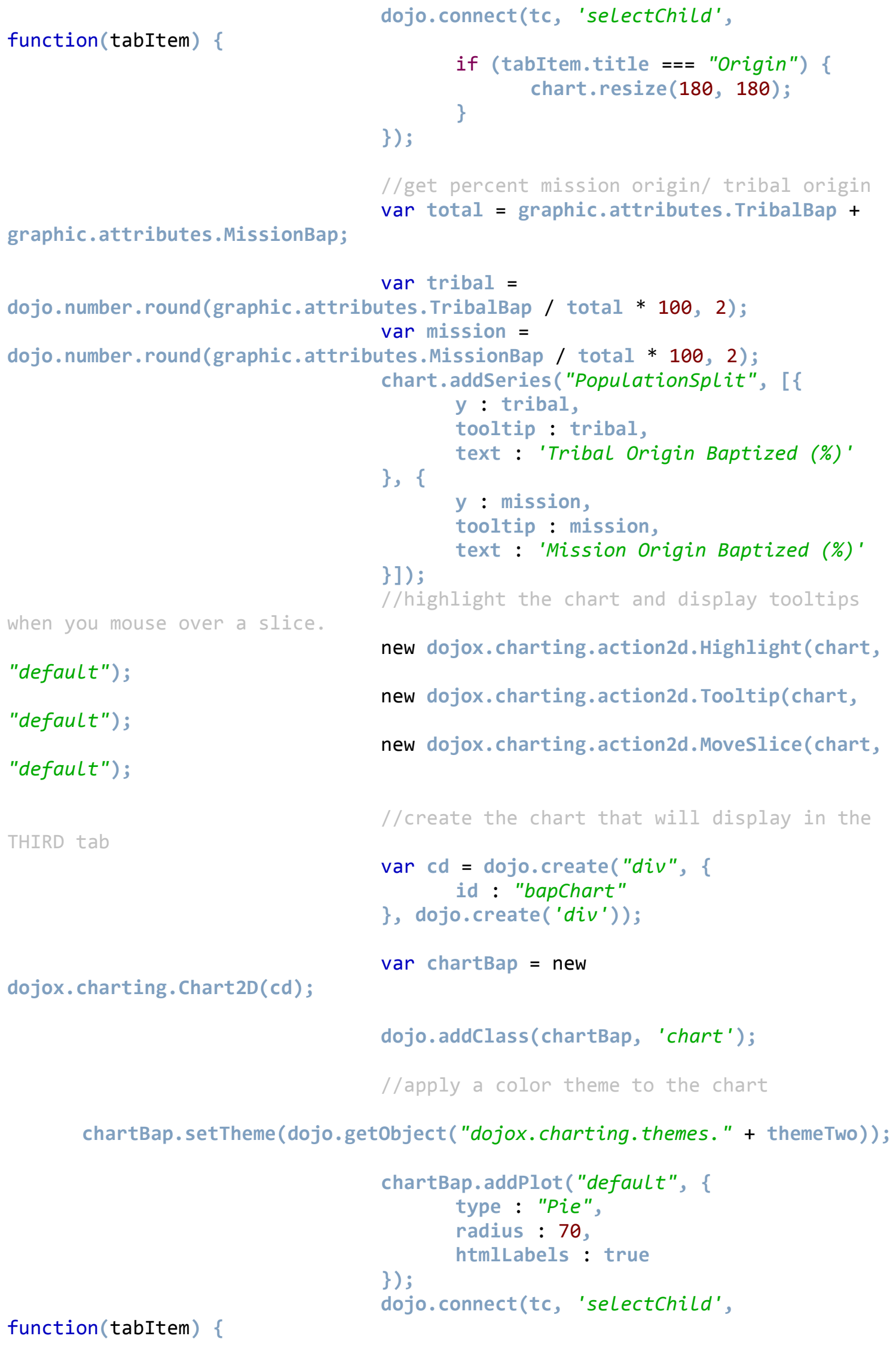




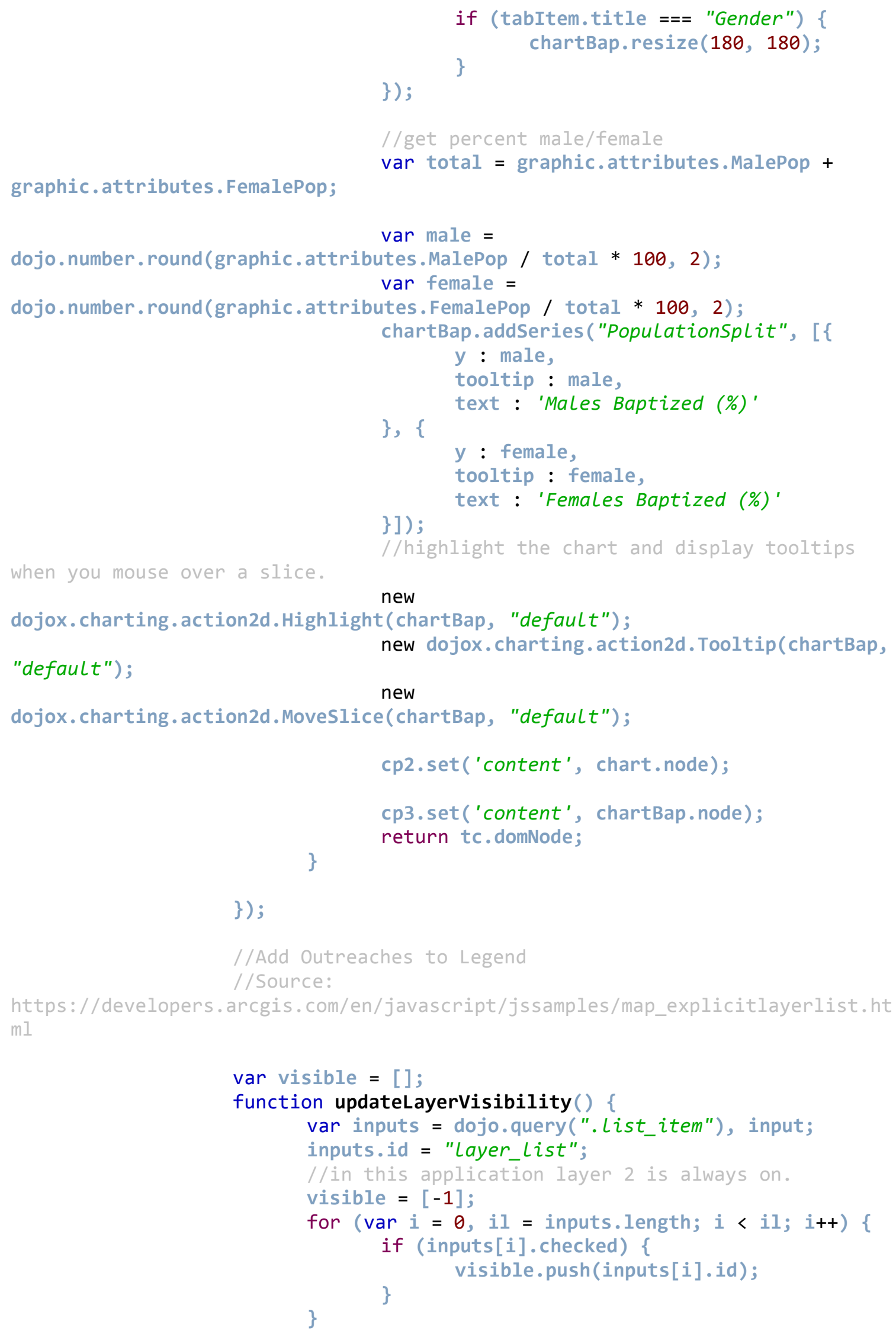




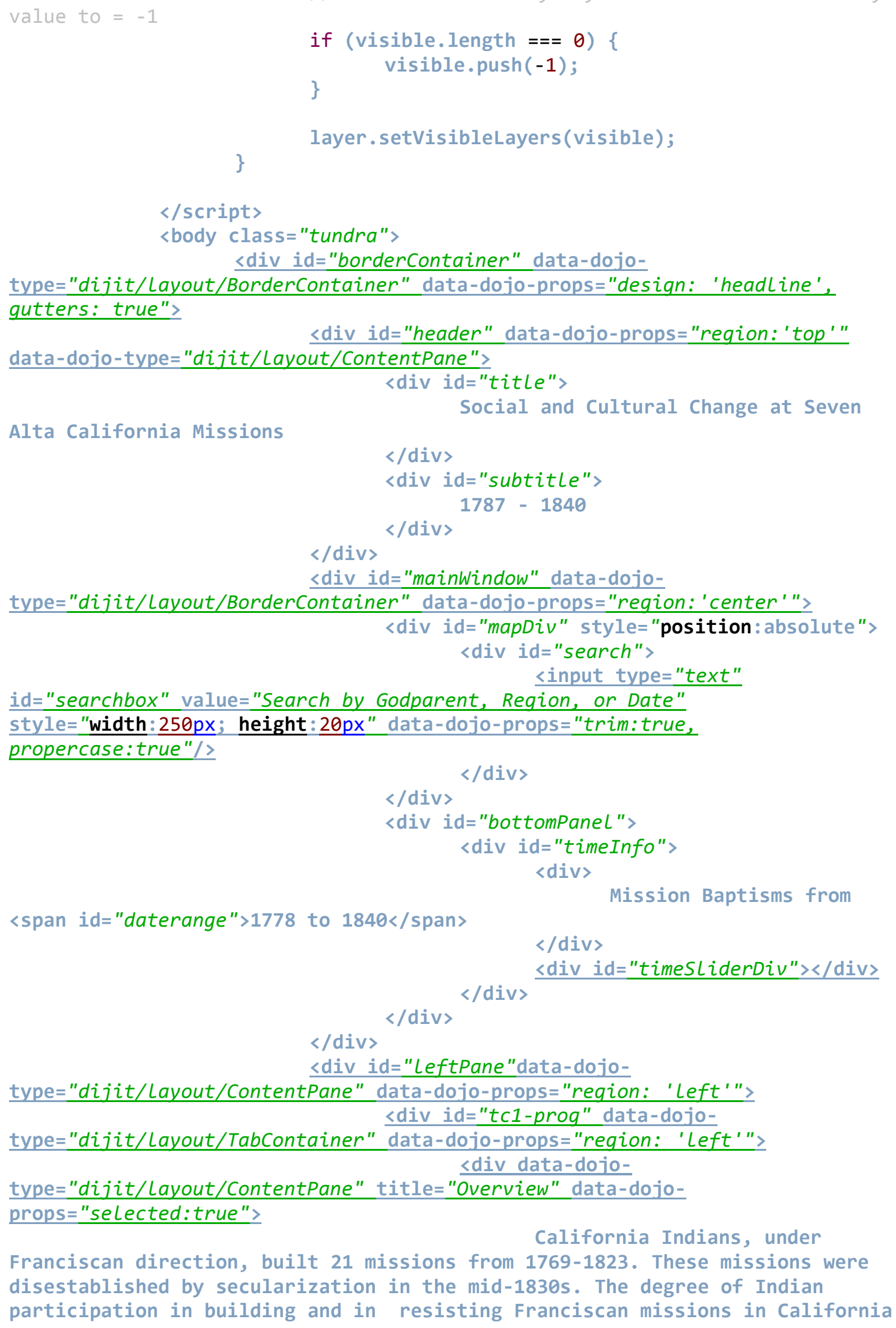


has been difficult for historians to discern from such traditional sources as correspondence and diaries. The digitization of priestly kept records at each mission begun in the late 20th Century and made available in the 21st, has opened new ways of analyzing the past.

$$
\langle/ b r\rangle\langle\text { br }\rangle
$$

$<a$

href="http://content.scu.edu/cdm/singleitem/collection/mission/id/194" target=" blank" id="external Link" $\rangle\langle/ a\rangle$

\section{$\langle/ b r\rangle$}

$\langle/ b r\rangle$

Every mission was ordered to keep registers of baptisms, marriages, and deaths. Franciscan priests were required to record specific information in each baptismal entry including the ego's baptism number, the ego's new Christian name, place of origin, baptism date, age, parents, and godparent. Access to the treasure trove of information provided by the digitalization of databases, combined with the addition of the derived fields of Indian language and modern day village/ranchería location, have permitted us to map mission outreach areas by language group and village. With these maps as a base, we have been able to use the tools of spatial analysis to see changes on the ground over time viewing the spread of Franciscan proselytization and the resultant Indian village collapse as their populations moved into the missions.

$$
\langle p\rangle\langle/ p\rangle
$$

Additional exciting prospects

offered by digitized mission databases have been the opportunity for comparative mission queries of such topics as patterns of mission entrance by ranchería, tribal born versus mission born longevity following baptism, and gender analysis as well as the ability to track individuals and their connections to other members of the mission community. From this work we are gaining powerful new insights into the dynamics and the tragedy of the California Mission period.

type="dijit/Layout/ContentPane" title="Introduction"
more about the mission and who lived there.

align="center" $\rangle /$ div $\rangle$

$$
\begin{aligned}
& \langle p / p\rangle \\
& \langle\text { div id="missionImq" }
\end{aligned}
$$

$\langle p \mid p\rangle$

Select one or multiple mission outreaches from the outreach tab to show where individuals baptized at each mission are from.

align="center" $\rangle\langle/$ div $\rangle$

$$
\langle p / p\rangle \text { 〈div id="outreachImg" }
$$

$\langle p \mid p\rangle$

Enter a Godparent Name, Region or Baptism Date in the search box to see geographic representation of individuals on the map and their records in the Search Results tab above. $\langle p / p\rangle$

align="center" $\rangle\langle/$ div $\rangle$ <div id="searchResult" $\langle p / p\rangle$ 
<input type=' checkbox'

class='List_item' id='5' value=5 onclick='updateLayerVisibility (); '/>

San Francisco de Asis

(Dolores) Outreach

$\langle$ br / $>$

<div id="outreach6"

align="center" $\rangle /$ div $\rangle$

$\leq p /\rangle$

<input type= 'checkbox'

class='List_item' id='6' value=6 onclick='updateLayerVisibility (); '/>

Santa Cruz Outreach

$\langle$ br / >

<div id="outreach7"

align="center" $\rangle\langle/$ div $\rangle\langle/$ span $\rangle$

$\langle/$ div $\rangle$

<div data-dojo-

type="dijit/Layout/ContentPane" title="Search Results" data-dojo-

props="spLitter:true">

$\langle/$ html $>$

$\langle/$ div $\langle/$ div $\rangle\langle/$ div $\rangle\langle$ div $\langle$ div id="grid" $\rangle\langle/$ div $\rangle$

